\title{
Impacts of assimilating dual-Doppler radar-retrieval winds on the TWRF predictions of Typhoon Nesat (2017)
}

\author{
Der-Song Chen ${ }^{1}$, Ling-Feng Hsiao ${ }^{1, *}$, Jia-Hong Xie ${ }^{1}$, Melinda S. Peng ${ }^{2}$, Chin-Tzu Fong ${ }^{1}$, \\ Pao-Liang Chang ${ }^{1}$, Wei-Ting Fang ${ }^{1}$, Jing-Shan Hong ${ }^{1}$, and Tien-Chiang Yeh $^{1}$ \\ ${ }^{1}$ Central Weather Bureau, Taipei City, Taiwan \\ ${ }^{2}$ University of Colorado, Colorado Springs, CO, USA
}

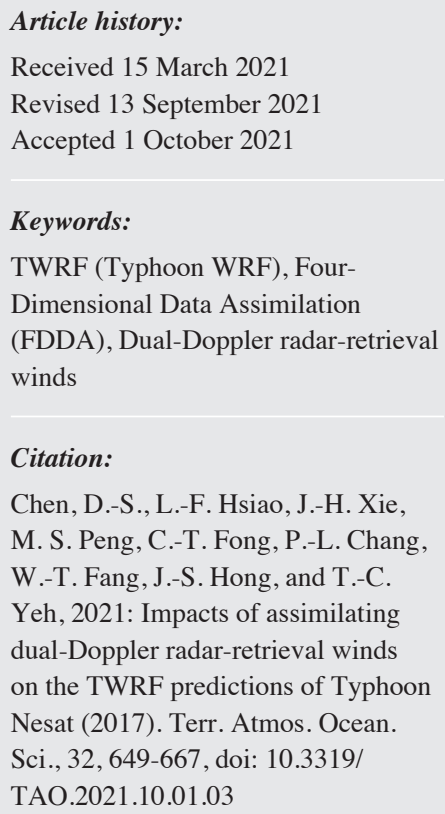

Citation:

Chen, D.-S., L.-F. Hsiao, J.-H. Xie, M. S. Peng, C.-T. Fong, P.-L. Chang, W.-T. Fang, J.-S. Hong, and T.-C. Yeh, 2021: Impacts of assimilating dual-Doppler radar-retrieval winds on the TWRF predictions of Typhoon Nesat (2017). Terr. Atmos. Ocean. Sci., 32, 649-667, doi: $10.3319 /$ TAO.2021.10.01.03

\begin{abstract}
The Central Weather Bureau in Taiwan successfully implemented a version of WRF coined as TWRF (Typhoon WRF) as the operational typhoon prediction system. The TWRF has two nested domains with $15 / 3 \mathrm{~km}$ resolution covering large areas over the western North Pacific, which has led to significant improvements of typhoon predictions over the previous version with coarser resolutions. Built upon this success, the WRF Four-Dimensional Data Assimilation (FDDA) system has been implemented in TWRF. This study investigates the impact of assimilating dualDoppler radar retrieval winds from eight sets of dual-Doppler radars using FDDA on the prediction of Typhoon Nesat (2017) that passed over Taiwan. The wind field retrieved with dual-Doppler radars has a vertical extent from 1 to $10 \mathrm{~km}$ and the horizontal resolution is $1 \mathrm{~km}$. After quality control and data thinning, the radar retrieval winds are assimilated using FDDA for two update cycles in addition to the existing hybrid 3DEnVar for all other observations in TWRF. Furthermore, we assimilate the additional radar data that become available during the 4-hour waiting period for the completion of the global model prediction to be used as the lateral boundary condition for TWRF. For Typhoon Nesat, the wind structure and rainfall forecasts are improved with the assimilation of radar-retrieval winds. The overall improvements demonstrated by this case study suggest potentially high impacts for improving the prediction of typhoon-related rainfall with assimilation of dual-Doppler radar data.
\end{abstract}

\section{INTRODUCTION}

Typhoons often post great threats to Taiwan's lives and properties. During the past 100 years, an average of 3 to 4 typhoons hit Taiwan each year and some storms have caused severe damage and loss of lives (Wu and Kuo 1999). World Bank (Dilley et al. 2005) identified Taiwan as having the highest frequency of combined natural disasters including typhoons, flooding, drought and earthquakes in the world. With two thirds of the land covered by mountains in the roughly $400 \mathrm{~km}$ by $200 \mathrm{~km}$ area, the majority of the population is located along the coastal regions that are significantly affected by typhoons. Typhoons approaching Taiwan produce strong winds and heavy rainfall that often are influenced by the complex terrain. The Central Weather

\footnotetext{
* Corresponding author

E-mail:lfh@cwb.gov.tw
}

Bureau (CWB) in Taiwan relies on numerical weather prediction (NWP) models to provide accurate and timely predictions of typhoons.

Observational data used at CWB include various types obtained from the global observing system. For example, observations from land stations and radiosondes have provided a stable source of information over the years, but their horizontal distribution is far from homogeneous globally. Although satellite observations are expanding rapidly and becoming a major source of information, they are more complicated to use in data assimilation. Data from landbased radars and airborne radars tend to be used mainly for localized applications.

Observations from a dense radar network in Taiwan have been used to monitor and improve predictions of typhoons, severe storms, flash floods, and debris flows (Chang et al. 2009). In addition, the three-dimensional wind 
structure has been constructed by combining the data from several Doppler radars (Chang et al. 2019). Their analysis indicated that the circulation characteristics in the inner core of the typhoon can be analyzed with the dual-Doppler wind retrievals. Such observed wind fields with high spatial-temporal resolution may be very useful for forecasting typhoon or other severe convective weather, particularly when a typhoon is approaching Taiwan.

Radar data assimilation has been demonstrated to be very useful for improving tropical cyclone predictions in NWP systems. Previous studies proposed several methods to assimilate radar in numerical models, such as variational data assimilation, ensemble Kalman filter, and the ensemble variational hybrid method (Xiao et al. 2007; Zhang et al. 2009; Aksoy et al. 2012; Li et al. 2012; Weng and Zhang 2012; Zhao et al. 2012a, b). These studies showed that radar data assimilation can provide a better representation of the vortex structure and reduce the intensity and track forecast errors. A nudging/Newtonian relaxation approach, which adjusts the model state variables towards observations during dynamic initialization, has also been used to assimilate radar observations into numerical models. Korsholm et al. (2015) added a horizontal velocity divergence term in the continuity equation to nudge the model state toward two-dimensional radar-derived precipitation. Huang et al. (2018) assimilated radar reflectivity data by nudging the hydrometeor and latent heating variables within a Weather Research and Forecasting (WRF)-based real time four-dimensional data assimilation and short-term forecasting system (RTFDDA; Liu et al. 2008a, b). Huang et al. (2018) showed improvements in forecasting convective systems, especially for improving precipitation forecast for the 0 3 hours nowcasting range. Elsberry et al. (2020) utilized a reprocessed GOES-16 atmospheric motion vector (AMV) dataset by adding a nudging term to the velocity equations in the COAMPS-TC dynamic initialization technique and successfully predicted a rapid intensification event in Hurricane Irma (2017).

A version of the WRF ARW (Advanced Research WRF) model (Skamarock et al. 2008) was implemented at CWB in 2004 and became its general-purpose regional prediction system in 2007. CWB continued to enhance the functionality of the model and configured a system dedicated for typhoon predictions which is identified as TWRF (Typhoon-WRF) and has been in operation at CWB since 2010. One of the major features of TWRF is the relocation procedure for TC-like vortex in the forecast system (Hsiao et al. 2010). Further improvements in TWRF include partial update cycle, hybrid 3DEnVar and upgrades of physical parameterization (Hsiao et al. 2012, 2015, 2020). The newest version with $15 \mathrm{~km} / 3 \mathrm{~km}$ resolution became operational in 2016 and has resulted in significant performance improvements (Hsiao et al. 2020). In addition to the hybrid 3DEnVar DA in TWRF, the WRF Four-Dimensional Data
Assimilation (FDDA) has been implemented in CWB. The FDDA system continuously assimilates observations during model integration through a nudging/Newtonian relaxation approach that forces the model state toward the observational state by adding artificial error correction terms to the model equations (Liu et al. 2008a, b).

There are basically two types of nudging (Anthes 1974; Hoke and Anthes 1976; Stauffer and Seaman 1990, 1994; Liu et al. 2006): one is analysis/grid nudging, which nudges the model-to-grid analysis; and the other is observational nudging, which nudges the model states toward point observations. The FDDA has the capability of doing either of these two nudging methods in multiple nesting environments, which made it ideal for adoption into TWRF. Another important advantage of the nudging-based data assimilation is its computational efficiency, as it only requires adding an additional tendency term. Thus, the nudging method can be used to frequently assimilate observations and has been adopted at many operational centers, such as Deutscher Wetterdienst (DWD), U. S. Army Test and Evaluation Commands (ATEC), and Meteorological Bureau of Shenzhen Municipality (Liu et al. 2008a, b; Stephan et al. 2008; Huang et al. 2018). Moreover, the adjustment through full-physics model dynamical and physical equations can adjust the model states toward dynamic and thermodynamic balance. Recent studies (Zhao et al. 2012a, b; Li et al. 2013; Wang et al. 2016) on radar-retrieved wind data assimilation indicate that it results in much improved structure and intensity analyses of typhoon. Furthermore, the assimilation of radar-retrieved winds also provides more accurate track forecasts and better precipitation prediction skills.

There are eight sets of dual-Doppler wind data retrieved from seven radars (see section 2.2) and analyzed around the Taiwan area, which are the primary datasets for this study to demonstrate the capability of using FDDA to ingest Doppler radar-retrieved winds to improve the TWRF forecasts. Typhoon Nesat (2017) is the case selected as it passed over Taiwan with ample radar data collected. The paper is organized as follows. Section 2 describes the latest version of TWRF and its operational configuration, introduces the FDDA system, describes the Doppler radars on Taiwan island, and describes the wind data collected for Typhoon Nesat (2017). Section 3 presents the forecasts and storm structures with and without the FDDA assimilation of the radar data. Section 4 contains the summary and conclusion.

\section{MODEL DESCRIPTIONS AND DA METHODOLOGY}

\subsection{Configuration of TWRF (Typhoon WRF)}

As indicated in section 1, the progressive development of TWRF has been described in Hsiao et al. (2010, 2012, $2015,2020)$. In addition to the vortex relocation procedure, a blending scheme based on an incremental spatial 
filtering scheme proposed by Yang (2005) to ameliorate accumulated model error has been implemented in TWRF. The blended analysis combines large-scale patterns (wavelength $>1200 \mathrm{~km}$ ) of the NCEP global analysis and the finer structure (wavelength $<1200 \mathrm{~km}$ ) of the high-resolution TWRF every 6 hours. Hsiao et al. (2015) demonstrated that adding a blending technique in TWRF not only reduced systematic errors resulting from DA cycling, it also improved the TC track and rainfall predictions over Taiwan. Apart from the benefits mentioned above, the blending strategy can also reduce errors introduced by the lateral boundary conditions in regional models (Yang 2005; Feng et al. 2020). The implementation of the outer loop in WRF three-dimensional variational (3DVAR) data assimilation system has allowed the utilization of more observations via the iteration procedure. The partial cycling strategy, which begins with a cold start from the analysis of Global Forecast System of the National Centers for Environmental Prediction (NCEP GFS) at 12 hours prior to the analysis time and is followed by two data assimilation cycles at 6-hour intervals, has provided better initial conditions. The cold start effectively mitigates the model-accumulated biases, and particularly the errors over the observation-sparse western Pacific area. Meanwhile, the two full assimilation cycles can reduce the TWRF model spin-up issue.

In summary, the key features in the current version of TWRF (V2.4) are (1) two nested grids covering large domains with $15 \mathrm{~km} / 3 \mathrm{~km}$ resolutions (Fig. 1a); (2) hybrid 3DEnVar DA with partial cycling; (3) relocation of the storm at the initial time; (4) blending of the global analysis with the separate TWRF analysis after the data assimilation cycle. The track and intensity forecasts of the current version have been improved significantly over the previous version, which had three-nested grids with $45 \mathrm{~km} / 15 \mathrm{~km} / 5 \mathrm{~km}$ resolutions. The main improvement of the current version over the previous version is due to higher resolutions covering a much larger area, as shown by the better statistical scores of the synoptic-scale forcing such as the root mean square errors (Hsiao et al. 2020).

\subsection{Dual-Doppler Radar Retrieval Winds}

Doppler radar emits electromagnetic wave pulses and measures the phase shift between the transmitted pulse and the backscattered echo. This phase difference of Doppler shift is used to estimate the radial velocity (along the radar beam) of the scattering target, such as raindrops. If two radars perform range-height indicator (RHI) scans (constant azimuth, multiple elevations) along azimuths separated by approximately $90^{\circ}$, then the intersection of the coordinated RHI planes represents a vertical set of points where dualDoppler wind syntheses are possible, and both wind speed and direction profiles can be retrieved (Gunter et al. 2015).

Eight sets of dual-Doppler wind synthetic analyses can be calculated from seven radars around the Taiwan area (Fig. 2). Due to different characteristics affected by the terrain, data from a pair of radars located on opposite sides of the Central Mountain Range are not generally used. The vertical extent of the radar wind detections is from 1 to $10 \mathrm{~km}$ with a spatial resolution of $1 \mathrm{~km}$. The wind fields from 2 to $8 \mathrm{~km}$ collectively from all radars are shown in Fig. 3 for Typhoon Nesat at 0600 UTC 29 July 2017. The distributions of the data at 4,6 , and $8 \mathrm{~km}$ are similar, with the best data coverage of the storm at mid-levels around $6 \mathrm{~km}$. The winds are more sparse at $2 \mathrm{~km}$ and provide little information on the storm structure. Between 4 and $9 \mathrm{~km}$, the storm center is
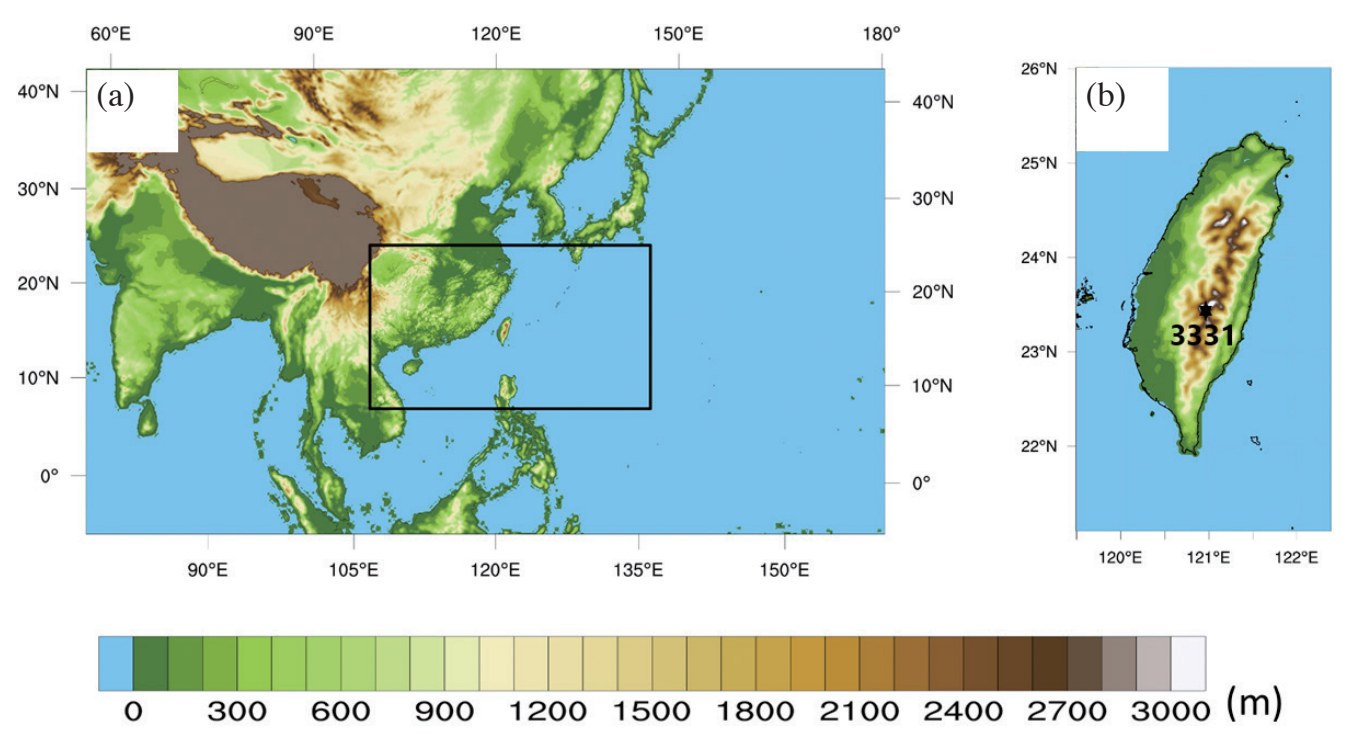

Fig. 1. (a) Two nested domains for the TWRF with $15 / 3 \mathrm{~km}$ resolution; (b) Terrain heights (m) on Taiwan, with the peak of $3331 \mathrm{~m}$ at the star location. 


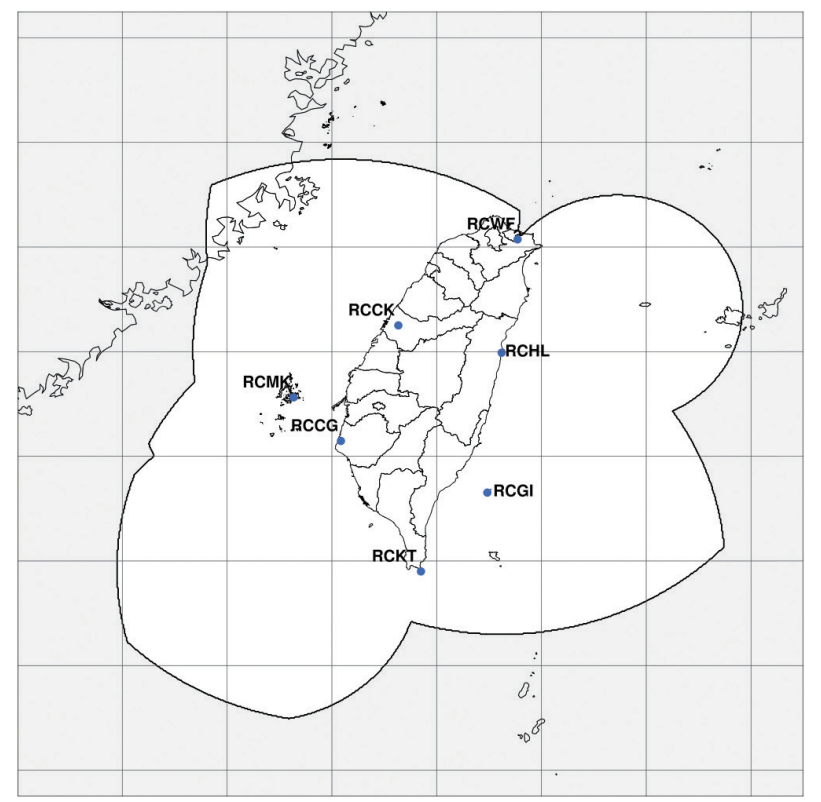

Fig. 2. Locations of the seven Doppler radars on Taiwan and their combined coverage from eight sets of dual-Doppler wind synthetic analyses.
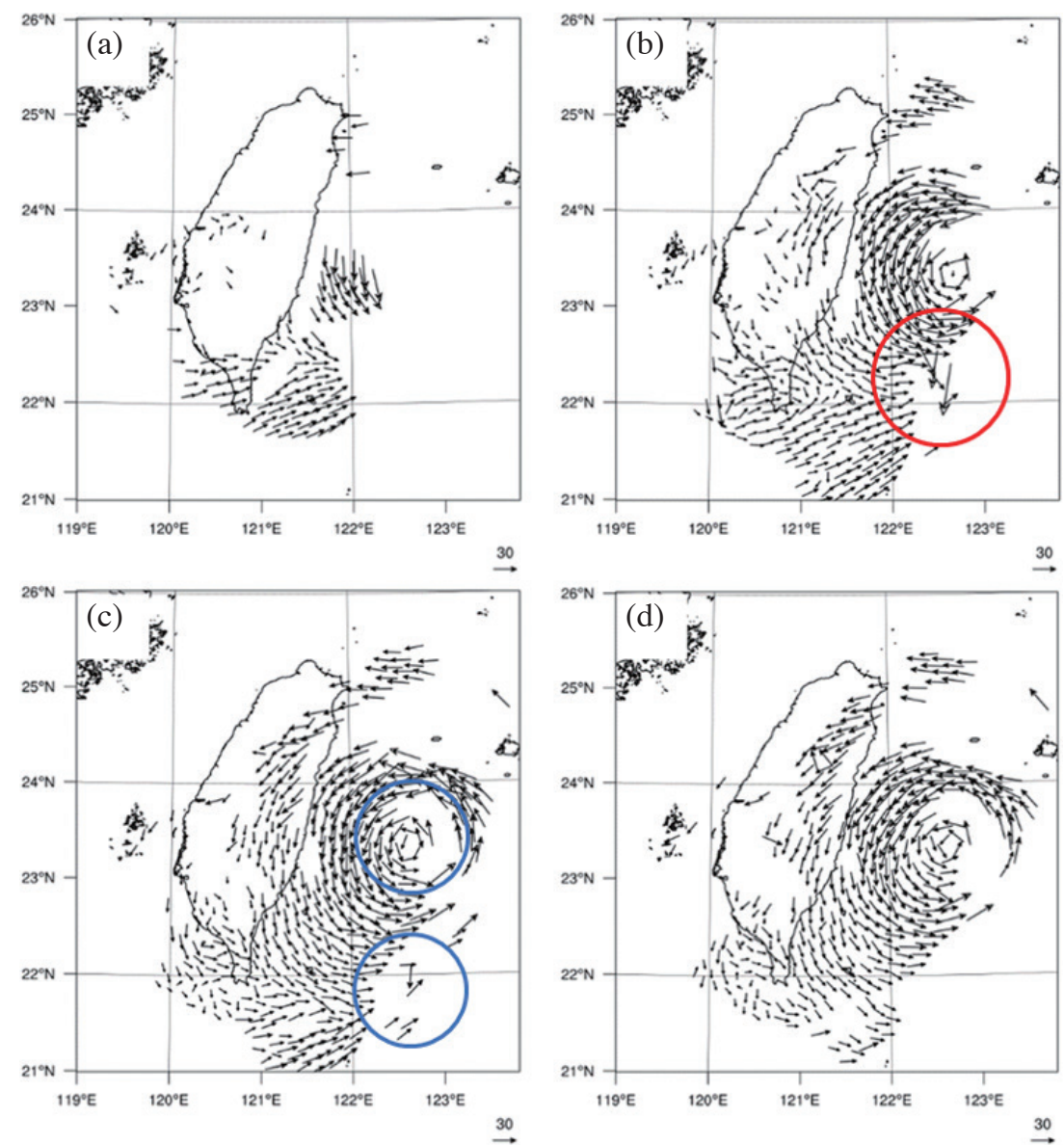

Fig. 3. Radar-retrieval wind fields ( $\mathrm{m} \mathrm{s}^{-1}$ ) at (a) $2 \mathrm{~km}$, (b) $4 \mathrm{~km}$, (c) $6 \mathrm{~km}$, and (d) $8 \mathrm{~km}$ on 0600UTC 29 July 2017 during the passage of Nesat. Note that wind speeds greater than 1.5 times the typhoon maximum wind speed are highlighted in the red circle, and wind directions within the radius of $15 \mathrm{~m} \mathrm{~s}^{-1}$ winds that deviates more than $60^{\circ}$ from a radial Rankine profile are highlighted in blue circle. 
consistently well defined.

In additional to standard quality control (QC) for the radar dataset, two additional QC steps are added. First, the wind data with a wind speed greater than 1.5 times of the typhoon maximum wind speed and exceeding one standard deviation were dropped. Second, if the wind direction within the radius of $15 \mathrm{~m} \mathrm{~s}^{-1}$ winds of the storm deviates more than $60^{\circ}$ from a radial Rankine profile, the data will be deleted. The storm center is based on best-track position prior to 0400 UTC 29 July and later positions are based on the radar-detected hourly centers.

With the large quantity of the radar data, data thinning is applied to save computational time as the focus of radar data assimilation is for short-term prediction and timely availability of the forecasts is critical. Several thinning strategies were tested to omit different amounts of data. As shown in Fig. 4, the horizontal thinning is staggered and also in the vertical to retain maximum information. The tests of the three approaches of skipping one, two and four data points resulted very small differences (figures not shown). Because skipping four data points decrease the computation time by half from 59 to 29 minutes, that thinning strategy was adopted. The wind distributions after the QC and the 4-point data thinning are shown in Fig. 5 at 2, 4,6 , and $8 \mathrm{~km}$, respectively, to be compared with the original data shown in Fig. 3. Note that radar winds with large wind speeds at $4 \mathrm{~km}$ were removed due to the first constraint (highlighted in red circle). In addition, the wind directions have greater symmetry around the center at $6 \mathrm{~km}$ after QC due to the second constraint (highlighted in blue circle).

The main purpose of this study is to investigate the effect of assimilating wind fields retrieved by the dual-Doppler radars through a FDDA nudging system when a typhoon is within the radar detection range. This case study is for Nesat (2017) that made landfall on northeast coast of Taiwan and exited on the northwest side. This is an ideal case with large radar coverage of the storm from its approach time until it passed over Taiwan. Due to the availability of the Doppler radar data in the proximity of the storm to Taiwan, the focus is on improved short-term prediction.

\subsection{WRF Four-Dimensional Data Assimilation (FDDA) System}

The FDDA system for WRF was developed to provide high-resolution and multi-scale data assimilation through a nudging/Newtonian relaxation approach that forces the model state toward the observational state by adding artificial error correction terms to model equations (Liu et al. $2008 \mathrm{a}, \mathrm{b})$. The nudging process in dynamic initialization is during the integration in the pre-forecast period, which is typically $6-12$ hours. Nudging can be applied to different model variables such as winds, temperature, and water vapor. The assimilated observations can be from different platforms, such as surface stations, radiosondes, profilers, aircraft, satellites, and radars. In our application, only radarretrieved winds will be incorporated in the FDDA while other conventional data are assimilated in the hybrid DA system for TWRF.

In FDDA, the dynamic initialization is spreading the information from the observation points to the neighboring model grid points in space and time (four dimensions: $x$, $y, z$, and $t$ ). In general, the time differential equation for a model variable $X^{m}$ can be expressed as:

$\frac{\partial X^{m}}{\partial t}=f\left(X^{m}, t\right)+G W\left(H Y^{o}-X^{m}\right)$

where the first term on the right side of the equation contains the background model forcing terms such as advection and physical parameterizations. The second term on the right side is the observational nudging term, which depends on the reciprocal of relaxation time scale $(G)$, weighting function ( $W$, a function of spatial distance and time in the window), and the difference between model the values and the observations $\left(Y^{\circ}\right)$ on the model grids $\left(H Y^{\circ}\right)$. The $H$ is the observation operator that projects the observations to the model grids. The horizonal part of the weighting function $W$ in Eq. (1) is defined as

$W_{x y}=\frac{R^{2}-D^{2}}{R^{2}+D^{2}} \quad 0 \leq D \leq R$

$W_{x y}=0 \quad D>R$

In this application of the FDDA with the Taiwan dualDoppler radar wind data, the horizontal radius of influence $R$ is set at $20 \mathrm{~km}$ considering the small scale of the radar data distribution and the high density of the data. Thus, the influence of the radar wind observation on a grid point at a distance $D$ from the observation decreases with the square of that distance.

The temporal weighting function $W$ in Eq. (1) is

$W_{t}=1 \quad\left|t-t_{0}\right|<\tau / 2$

$W_{t}=\frac{\tau-\left|t-t_{0}\right|}{\tau / 2} \quad \tau / 2 \leq\left|t-t_{0}\right| \leq \tau$

As illustrated in Fig. 6, the temporal weighting function is 1 within the time window $\tau$ centered at the observation time $t_{0}$ and decreases linearly to zero at the ends of the time window at $t_{0}-\tau$ and $t_{0}+\tau$. The window length $\tau$ is set to 40 minutes for this study based on the high temporal resolution of the radar data. More details for the FDDA can 
(a)

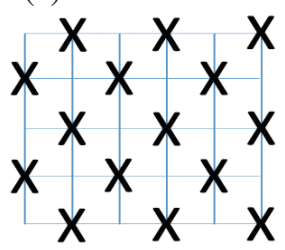

(b)

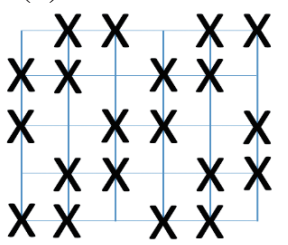

(c) $x \times x x$
$x \quad x \times x x$
$x \times x x x$
$x \times x \quad x x$
$x \times x \times x$

Fig. 4. Data thinning strategies that were tested. with a spatial resolution of $1 \mathrm{~km}$. (a) Skips of every other grid point; (b) skips of two points in each direction; and (c) skips of four points along a diagonal line. The horizontal lines represent the vertical levels and show the staggering when skipping data points horizontally.
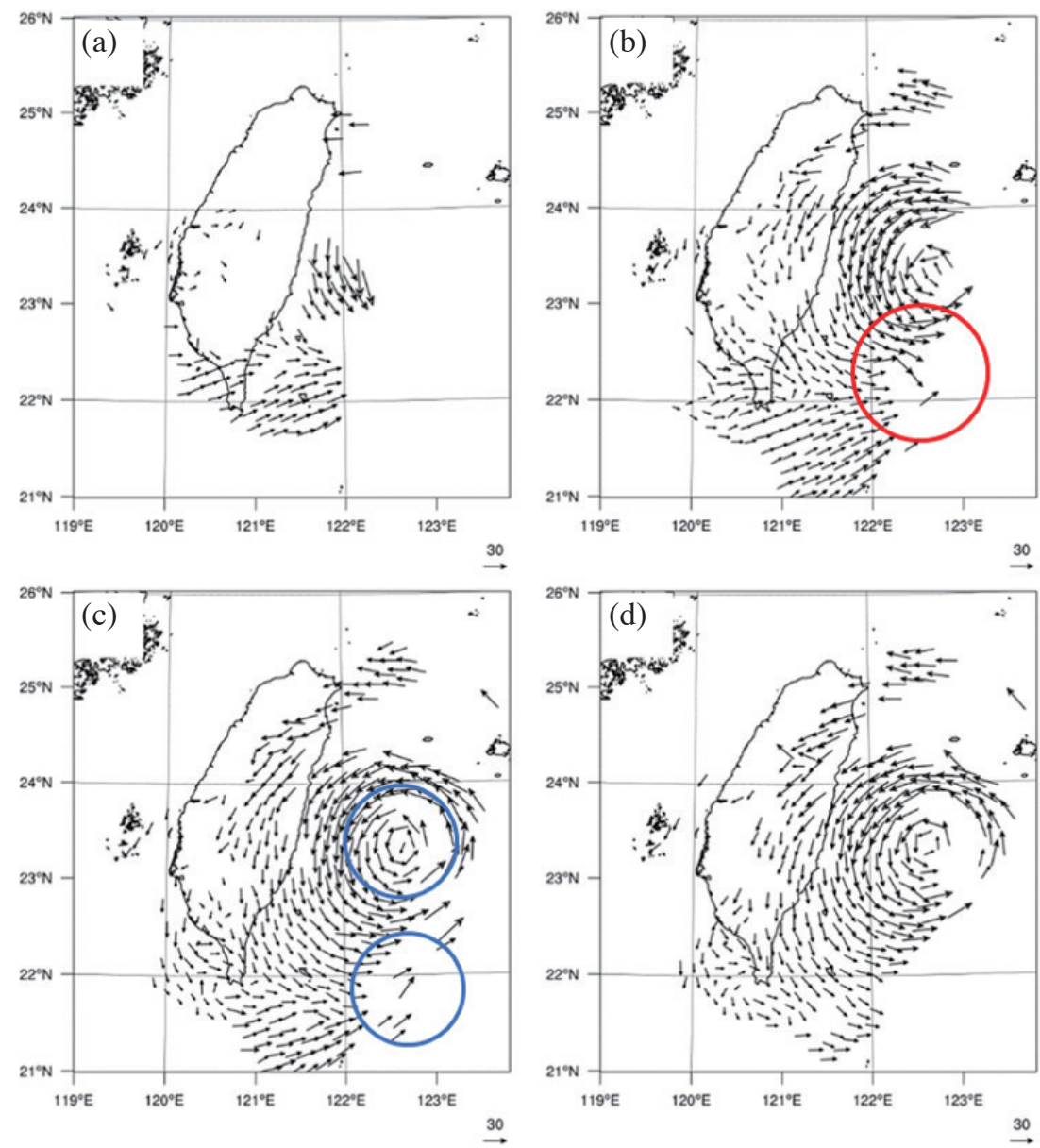

Fig. 5. Wind fields $\left(\mathrm{m} \mathrm{s}^{-1}\right)$ retrieved from the dual-Doppler radars synthetic analyses on 0600 UTC 29 July 2017 after the quality control and after 4-point data thinning as in Fig. 4 versus the coverage in Fig. 3. Note that radar winds with large wind speeds at 4 km were removed (highlighted in red circle), and the wind directions that have greater symmetry around the center at $6 \mathrm{~km}$ after QC (highlighted in blue circle). 


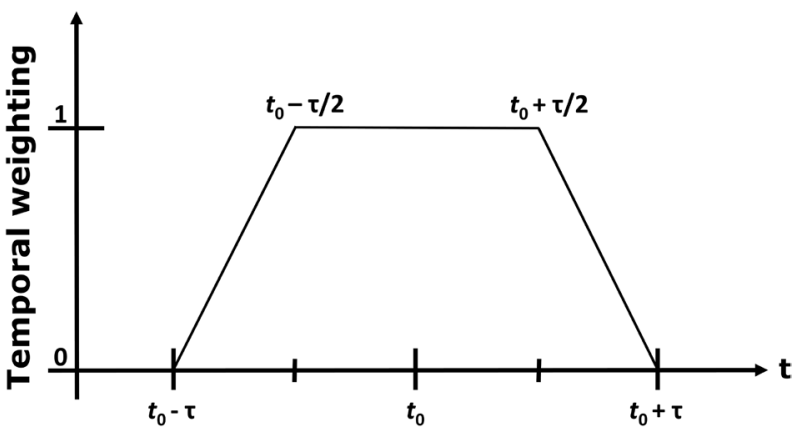

Fig. 6. Temporal weighting function in the FDDA nudging for radar wind observation at time $t_{0}$ and $\tau=40$ minutes.

be found in Liu et al. (2008a, b) and Pan et al. (2015a, b).

\section{FORECASTS OF TYPHOON NESAT (2017) WITH DUAL-DOPPLER RADAR-RETRIEVAL WINDS}

As with most regional prediction systems, TWRF tends to accumulate biases after extended forecast periods. Instead of the full update cycle conventionally used in operational numerical prediction systems, a partial update cycle is used in TWRF to eliminate the long-term biases while still taking advantage of an update cycle to retain the smaller-scale features (Hsiao et al. 2015). Namely, TWRF is initialized from the global analysis two 6-hour cycles before each forecast run (the gray part in Fig. 7), which is designated as partial cycling. This operational TWRF will be the control experiment and referred as "CTRL". In an earlier stage of this study, only a small improvement was found from assimilating the radar data using FDDA, which may be attributed to a short-lived impact of the nudging of radar-wind observations after the beginning of the forecast when the nudging had ended. The new approach is to take advantage of the 4-hour period after the synoptic time during which the global model analysis and forecast are being completed to provide the lateral boundary conditions for the regional model. The new approach is to take advantage of the collection of additional radar data during this 4-hour window to continue assimilating the radar-retrieved wind data (the red times in Fig. 7). This assimilation experiment will be referred as "FDDA+4h".

The impact of the dual-Doppler retrieval winds on typhoon prediction is investigated with the forecast of Typhoon Nesat (2017) for two forecast cycles starting on 0000 UTC and 0600 UTC 29 July 2017, respectively. The 6-hour-accumuated rainfalls from the control, FDDA, and FDDA+4h forecasts starting on 0000 UTC 29 July are compared with the Quantitative Precipitation Estimation and Segregation Using Multiple Sensor (QPESUMS; Chang et al. 2021) system (Fig. 8a). The rainfall from the FDDA after two update cycles (Fig. 8c) is very similar to the one in the CTRL00 without assimilating the radar data
(Fig. 8b). Note that the excessive rainfall in the southern part of Taiwan in the CTRL00 (Fig. 8b) remains after two FDDA cycles with the radar data (Fig. 8c). When additional radar data are assimilated in the first 4-hour of the forecast of the FDDA+4h00 experiment, a significant improvement is achieved by reducing the large biases over the land (Fig. 8d) comparing against the verification (Fig. 8a). These forecast precipitation patterns are generally closely associated with the wind distribution. Note that the wind speeds surrounding Nesat in Figs. 9d and e with the assimilation of radar data are reduced relative to the 0000 UTC (Fig. 9a) and 4-hour forecast (Fig. 9b) in the CTRL00, which results in a decrease of the rainfall and reduces the over forecast bias. The vertical cross-sections illustrating the differences between the 4-hour forecast fields (Fig. 9c) and the fields at four hours at the end of the assimilation FDDA+4h00 (Fig. 9f) indicate improvements at all levels above $2 \mathrm{~km}$ where the radar wind data are available.

The key question is why the assimilation of the radar data with two update cycles had only a small effect while the continued 4 hours assimilation had a much larger impact? The first reason maybe that the TWRF partial cycling blends the global analysis for wavelengths greater than $1200 \mathrm{~km}$ with its own analysis (Hsiao et al. 2015), which likely reduces the effect of assimilating the radar data. The second reason is that the additional 4 hours of data assimilation in the FDDA+4h00 experiment assimilates more radarwind data that are closer to the forecast time, and therefore is more effective in affecting the subsequent forecast. Consequently, only the FDDA+4h experiment fields will be compared with the CTRL fields in assessing the impacts. Table 1 provides the description of experimental design. Since the original FDDA version with FDDA only during the two partial cycles was already tested for the 0000 UTC forecast, it is not included in the table.

\subsection{Forecasts Starting on 0000 UTC 29 July}

The forecast wind fields with and without assimilating the radar wind data are first compared. Since the radar wind 


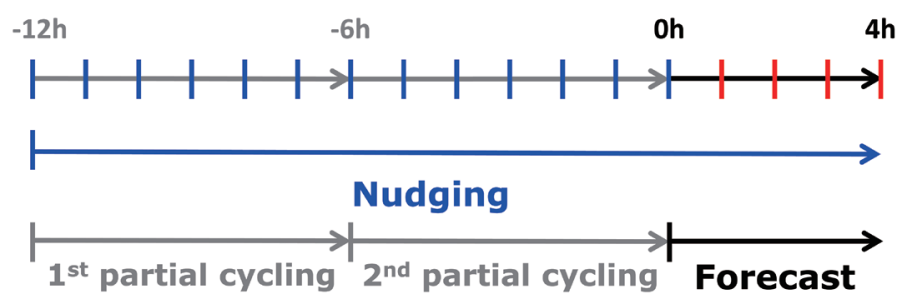

Fig. 7. Schematic diagram depicting the normal partial cycling (gray labeling) application of the FDDA for a forecast cycle beginning at time 0 hour In this FDDA+4h assimilation experiment, the radar-retrieval wind data are continued to be assimilated during the first four hours of the forecast cycle (red time lines).
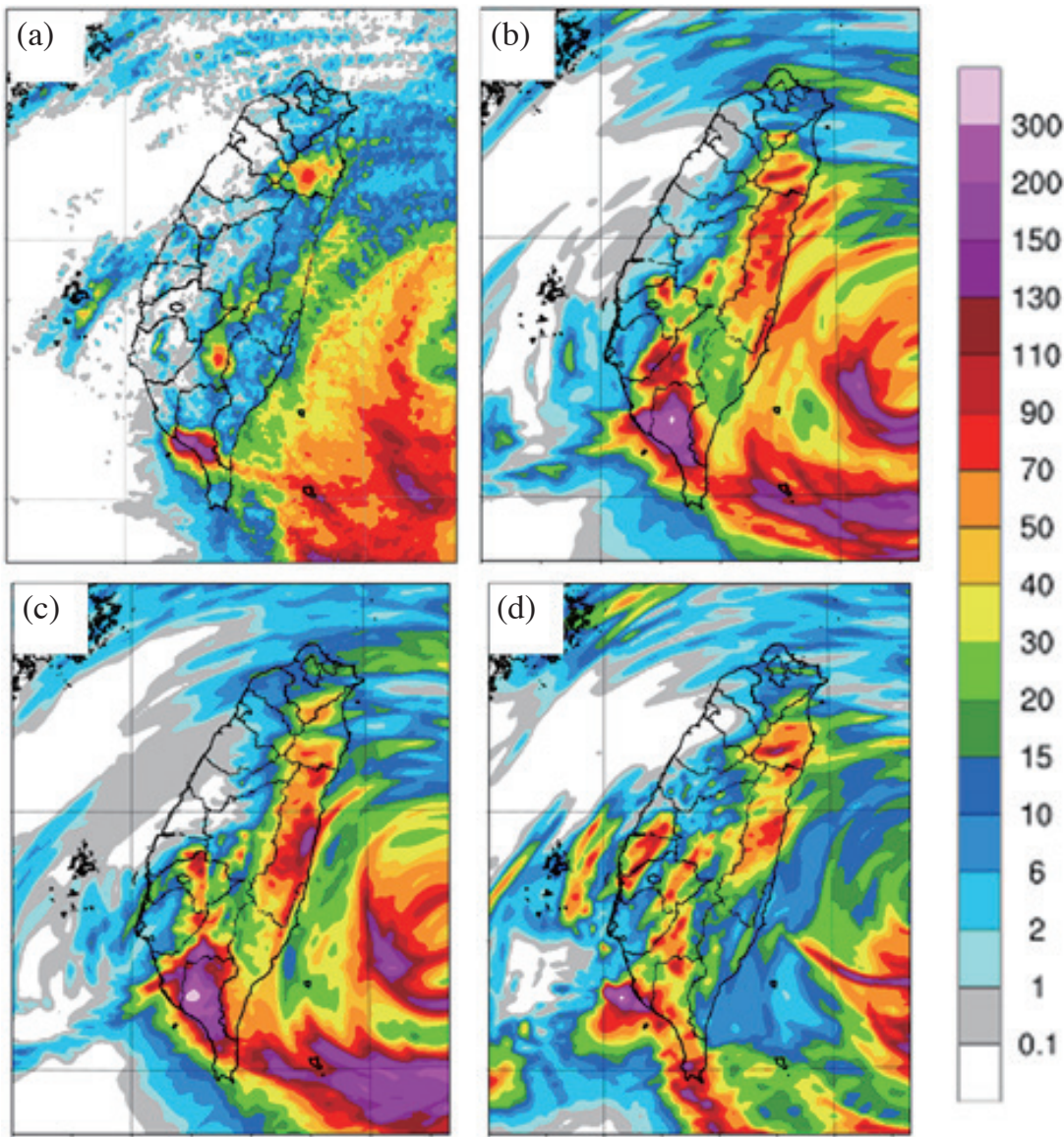

\section{0}

15

10

6

2

1

0.1

Fig. 8. Six-hour accumulated rainfall (mm) from forecasts initiated at 0000 UTC 29 July 2017 compared with the QPESUMS observations in panel (a); (b) operational run without assimilation of radar-retrieval winds using FDDA; (c) with radar-retrieval winds using FDDA in the two 6 h update cycles; and (d) FDDA with additional $4 \mathrm{~h}$ assimilation after the forecast initial time (FDDA+4h00). 

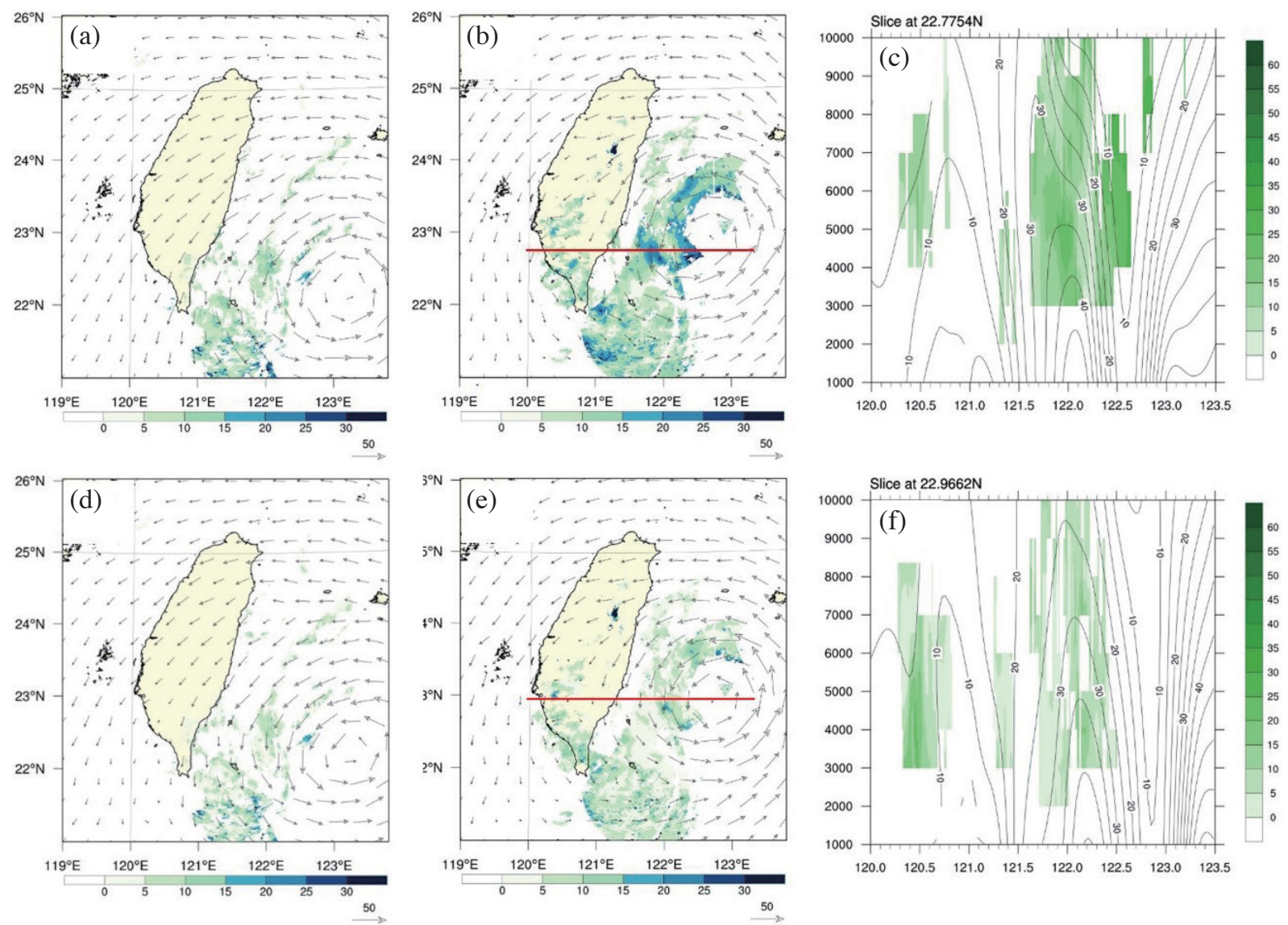

Fig. 9. Wind vector $\left(\mathrm{m} \mathrm{s}^{-1}\right)$ fields and the differences of these winds from the radar-retrieval winds (shaded every $\left.5 \mathrm{~m} \mathrm{~s}^{-1}\right)$ in the horizontal at $3 \mathrm{~km}$ at 0000 UTC 29 July (a) from the CTRL00 forecast without FDDA, (b) CTRL00 forecast at 0400 UTC, and (c) in a vertical (m) cross-section of horizontal winds across Taiwan and through the typhoon center [red line in (b)]. (d), (e), (f) as in (a), (b), (c), except from FDDA+4h00 experiment. Wind vector magnitudes are indicated by the color scales on the right side, and by a $50 \mathrm{~m} \mathrm{~s}^{-1}$ vector length below panels (a), (b), (d), and (e).

Table 1. Design of experiments with/without using FDDA radar-retrieval wind for Typhoon Nesat starting on 0000 UTC and 0600 UTC 29 July 2017.

\begin{tabular}{c|cc}
\hline & $\begin{array}{c}\text { Control run without using } \\
\text { FDDA }\end{array}$ & $\begin{array}{c}\text { Using FDDA in the partial update cycles, and with additional } 4 \text { hours assimilation after } \\
\text { the forecast initial time }\end{array}$ \\
\hline 17072900 & CTRL00 & FDDA+4h00 \\
17072906 & CTRL06 & FDDA+4h06 \\
\hline
\end{tabular}

data are used as the verification at the valid times, differences between the forecast and the verification are displayed only where the radar wind data are available. The CTRL00 forecast without the radar wind data and the assimilation using FDDA+4h00 for Typhoon Nesat starting at 0000 UTC 29 July are shown in the top and the bottom rows of Fig. 10 respectively. Within the detectable range of the dual-Doppler radars, the 6-hour wind speeds near the storm center in the CTRL00 forecast (Fig. 10a) valid at 0600 UTC 29 July are higher than in the forecast from the FDDA+4h00 (Fig. $10 \mathrm{~d}$ ). As revealed by the wind differences (shading) and the wind vectors, the wind differences for the FDDA+4h00 fields (Fig. 10d) are much closer to the verifying radar data.
This improvement is not surprising as this 0600 UTC time that the assimilation of the radar data in FDDA+4h00 had been completed just 2 hours earlier. Two hours later at 0800 UTC, the center of the storm in the CTRL00 (Fig. 10b) has deviated more from the verification, and thus the vector differences are much larger than for the FDDA+4h00 (Fig. 10e) that has the correct center location. By 1000 UTC, which is right before Nesat made landfall, the wind differences between the two experiments are even larger (Figs. 10c and f), with the wind speeds more over-predicted in the CTRL00 than in the FDDA+4h00. The FDDA+4h00 predicted positions are nearly on the spot (shown more clearly by the tracks in Fig. 11), especially at 0600 UTC (Fig. 10e). 
The forecast tracks and the best-track for this case starting on 0000 UTC 29 July 2017 are displayed in Fig. 11. Before making landfall, the forecast storm positions in the CTRLO0 are slightly south of the best track position, which is consistent with the wind differences in Figs. 10c and $\mathrm{f}$. Meanwhile, the forecast track in FDDA+4h00 is slighter closer to the best-track upstream of Taiwan. After Nesat passed over Taiwan, the two track forecast positions are both to the south of the best-track. However, the track forecast from FDDA+4h00 is noticeably closer to the best track at 1800 UTC 29 July. The track forecast errors for this case are summarized in Table 2. Even though the CTRL forecast does have rather small track errors, the FDDA+4h00 is able to further improve forecast errors by about $20 \mathrm{~km}$ during the 6-hour to 18-hour forecast period. In addition to contributing to smaller track errors, the FDDA+4h00 including an additional 4 hours of wind retrievals has a large impact on the precipitation over the island, which is discussed in the next segment.

The precipitation associated with passing typhoons pose great threats to Taiwan with flooding and possibly landslides. Thus, accurate short-term warnings of torrential rainfall are critical, which is also valuable information for managing dam capacity. Here, the instantaneous precipitation patterns are inferred in terms of the simulated refractivity from the model after 6, 8, and 10 hours (Fig. 12). Overall, the precipitation patterns from the FDDA+4h00 forecast (Figs. 12g, h, i) agree more closely with the observed precipitation (Figs. 12a, b, c) than those from the CTRL00 forecast (Figs. 12d, e, f). The standout feature is the retaining of an eye at $1000 \mathrm{UTC}$ in the FDDA+4h00 forecast (Fig. 12i), which is 6 hours after the ending of the FDDA assimilation. Recall that the symmetric structure of the storm had dissipated in the CTRLO0 forecast in Fig. 10c compared to a better center position and wind structure in FDDA $+4 \mathrm{~h} 00$ forecast shown in Fig. 10f. Some of the degradation of the reflectivity in the CTRL00 forecast (Fig. 12f) is because of the more rapid translation such that the storm structure is impacted by the terrain at 0000 UTC. Thus, storm motion differences have impacted the inferred precipitation patterns with a distinct maximum off the east coast of Taiwan in the FDDA+4h00 forecast (Fig. 12f).

The 6 hours accumulated rainfall from the CTRLO0 and FDDA+4h00 forecasts are compared with the QPESUM estimates in Fig. 13 to illustrate the accumulated effect of assimilating the radar-retrieved wind data. During the first 6 hours between 0000 UTC and 0600 UTC 29 July, little rain was observed over the island except for a very small area in the southern part of Taiwan (dashed circle in Fig. 13a). In the CTRL00 forecast (Fig. 13b), excessive accumulated rain is predicted not only in southern Taiwan, but also to the east of the Central Mountain Range (CMR) and extending to the northeast Taiwan. While the FDDA+4h00 forecast (Fig. 13c) has a better prediction in southeast Taiwan, it also has produced excessive rain to the east of the CMR during this period. Because the 6-hour forecast positions from both the CTRL00 and FDDA+4h00 forecast are very close to the best-track position (Fig. 11), the excessive precipitation accumulations in the model forecasts most likely are not related to incorrect track forecasts. When the cyclonic circulation of the typhoon (Figs. 10a and d) encountered the CMR from the east side of the mountain, up-slope rain will have been produced. Thus, the 0 - 6 hours excessive rain accumulations on the eastern side of the CMR likely stemmed from the positive wind biases in both the CTRLOO and the FDDA+4h00 forecasts.

During the next 6 hours from 0600 UTC to 1200 UTC, the FDDA+4h00 forecast (Fig. 13f) is only slightly improved over the CTRL00 forecast (Fig. 13e) in northeast Taiwan (Fig. 13d) where the leading edge of Nesat is interacting with terrain. During this period, the faster transition speeds in both forecasts (Fig. 11) likely contributed to the localize rain maximum on the western side of the CMR north of $24^{\circ} \mathrm{N}$ where the cyclonic circulation of the storm would have impinged on the CMR from the west side. As indicated in Fig. 11, the CTRL00 forecast predicted that Nesat would move further south along the west coast of Taiwan and then linger longer off the west coast. Not only could this explain the rainfall deficit over the region north of $24^{\circ} \mathrm{N}$, the southeastern rainfall maximum might be attributable to a longer period during which the Nesat circulation may have interacted with the summer southwesterly background flow. By contrast, the FDDA+4h00 forecast from 1200 UTC to 1800 UTC (Fig. 13i) has a substantially improved accumulated rain over the CTRL00 (Fig. 13h). Note that the heavy rainfall over the central western Taiwan (Fig. $13 \mathrm{~g}$ ) is well predicted by FDDA+4h00 forecast, which is critically important as this rainfall maximum (Fig. 13g) is over a densely populated region of Taiwan. Not only does the CTRLO0 forecast greatly under-predict this central-western maximum, it also has the maxima accumulated rain over the southeastern region of Taiwan that is more sparsely populated (Fig. 13h). Even though these are seemingly small differences from the FDDA +4 h00 track forecast (Fig. 11), the effects on the 6 hours accumulated precipitation can be profound mainly due to the impact of the CMR on the typhoon related rainfall (Hendricks et al. 2016). This investigation highlights the importance of accurate track prediction for a small mountainous island like Taiwan with localized rainfall extremes as the tropical cyclone circulation interacts with that terrain.

\subsection{Forecast Starting on 0600 UTC 29 July}

The second case study starts from 0600 UTC 29 July when Typhoon Nesat was just 6 hours from landfall on northeastern Taiwan, and thus was well within Doppler range (Fig. 14). The track forecasts by the CTRL06 and the FDDA+4h06 are very close to each other and have similar 

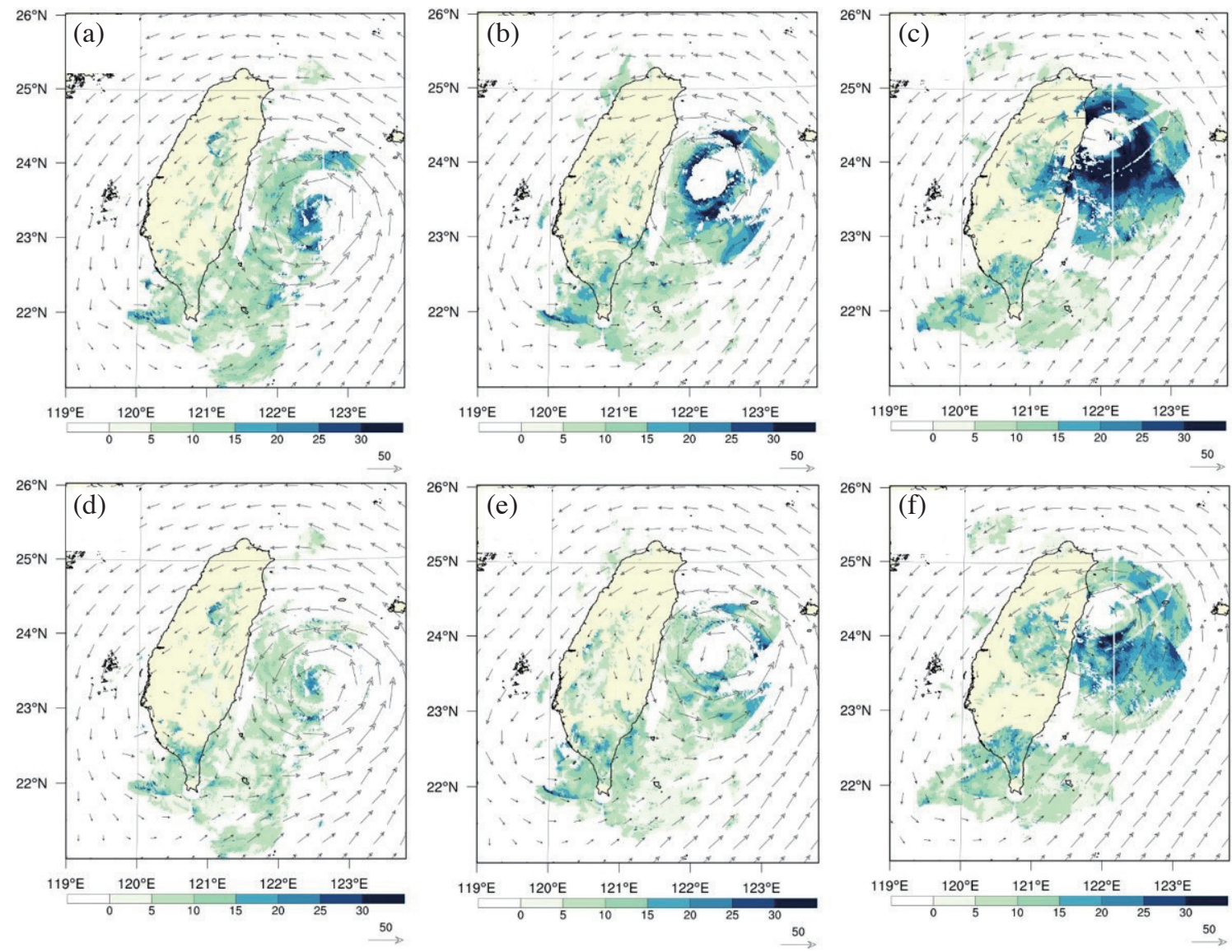

Fig. 10. Initial $3 \mathrm{~km}$ wind vectors $\left(\mathrm{m} \mathrm{s}^{-1}\right)$ for forecasts from 0000 UTC 29 July are given in Figs. 9a and d with vector magnitudes indicated by the color scales and by a $50 \mathrm{~m} \mathrm{~s}^{-1}$ vector length below each panel. Forecast wind vectors fields and differences from the radar-retrieval winds (shaded every $5 \mathrm{~m} \mathrm{~s}^{-1}$ ) are given at 0600 UTC (a) (d), at 0800 UTC (b) (e), and at 1000 UTC (c) (f) 29 July. The upper panels are from the CTRL00 without FDDA and the lower panels are from FDDA+4h00.

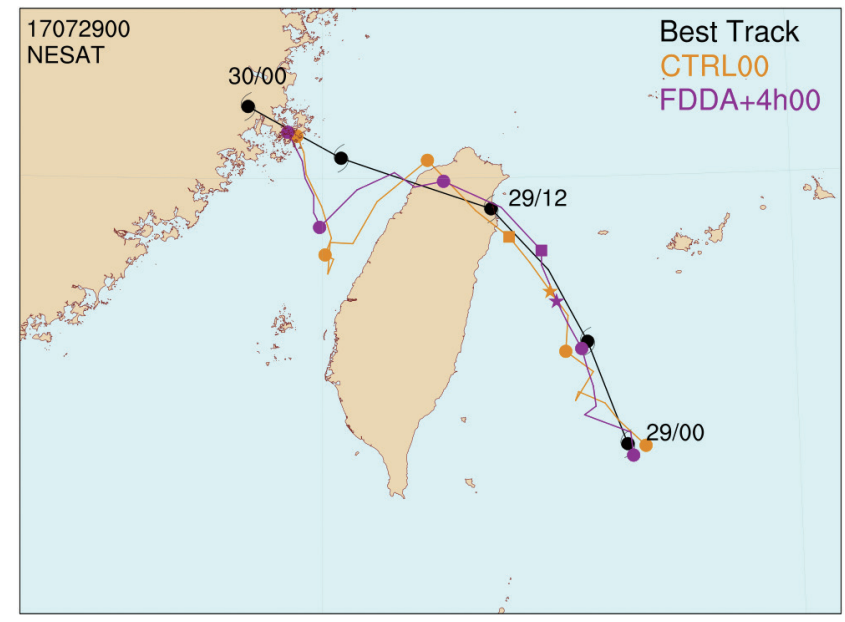

Fig. 11. Best track according to the CWB (black) and the TWRF CTRL00 (orange) and with FDDA+4h00 assimilation (purple) forecast tracks for Typhoon Nesat starting at 0000 UTC 29 July 2017. The star and square symbols are the forecast storm positions at 0800 and 1000 UTC, respectively. 
Table 2. Track forecast errors $(\mathrm{km})$ for Typhoon Nesat starting from 0000 UTC and from 0600 UTC 29 July 2017 respectively, and the average of the two forecasts. Both forecasts are based on the wind fields on the $3 \mathrm{~km}$ domain.

\begin{tabular}{c|c|ccccc}
\hline \multicolumn{2}{l|}{} & $\mathbf{0 h}$ & $\mathbf{6} \mathbf{h}$ & $\mathbf{1 2} \mathbf{h}$ & $\mathbf{1 8} \mathbf{h}$ & $\mathbf{2 4} \mathbf{h}$ \\
\hline \multirow{2}{*}{17072900} & CTRL00 & 13 & 26 & 86 & 105 & 80 \\
& FDDA+4h00 & 12 & 8 & 59 & 78 & 78 \\
\hline \multirow{2}{*}{17072906} & CTRL00 & 17 & 19 & 43 & 78 & \\
& FDDA+4h06 & 9 & 13 & 50 & 78 & \\
\hline \multirow{2}{*}{ Average (17072900,17072906) } & CTRL & 15 & 23 & 65 & 92 & 80 \\
& FDDA+4h & 11 & 11 & 55 & 78 & 78 \\
\hline
\end{tabular}
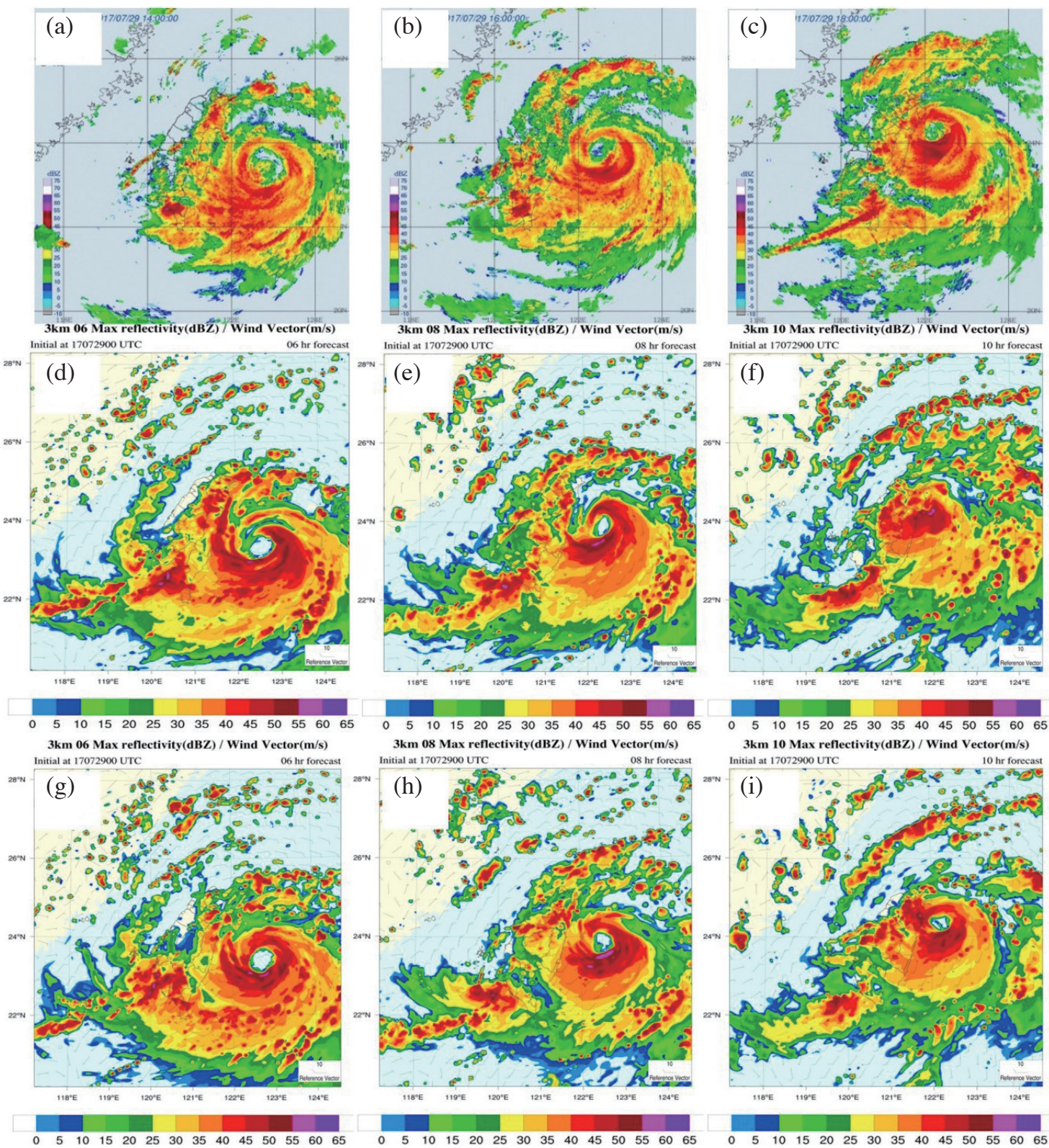

Fig. 12. Simulated radar reflectivity (dBZ) at 0600 UTC, 0800 UTC, and 1000 UTC related to the TWRF forecasts starting from 0000 UTC 29 July. Top panels (a) (b) (c): observations; middle panels (d) (e) (f): CTRL00 forecast without assimilation of radar-retrieval winds; bottom panels (g) (h) (i): forecast of FDDA+4h00 with radar-retrieval winds. 

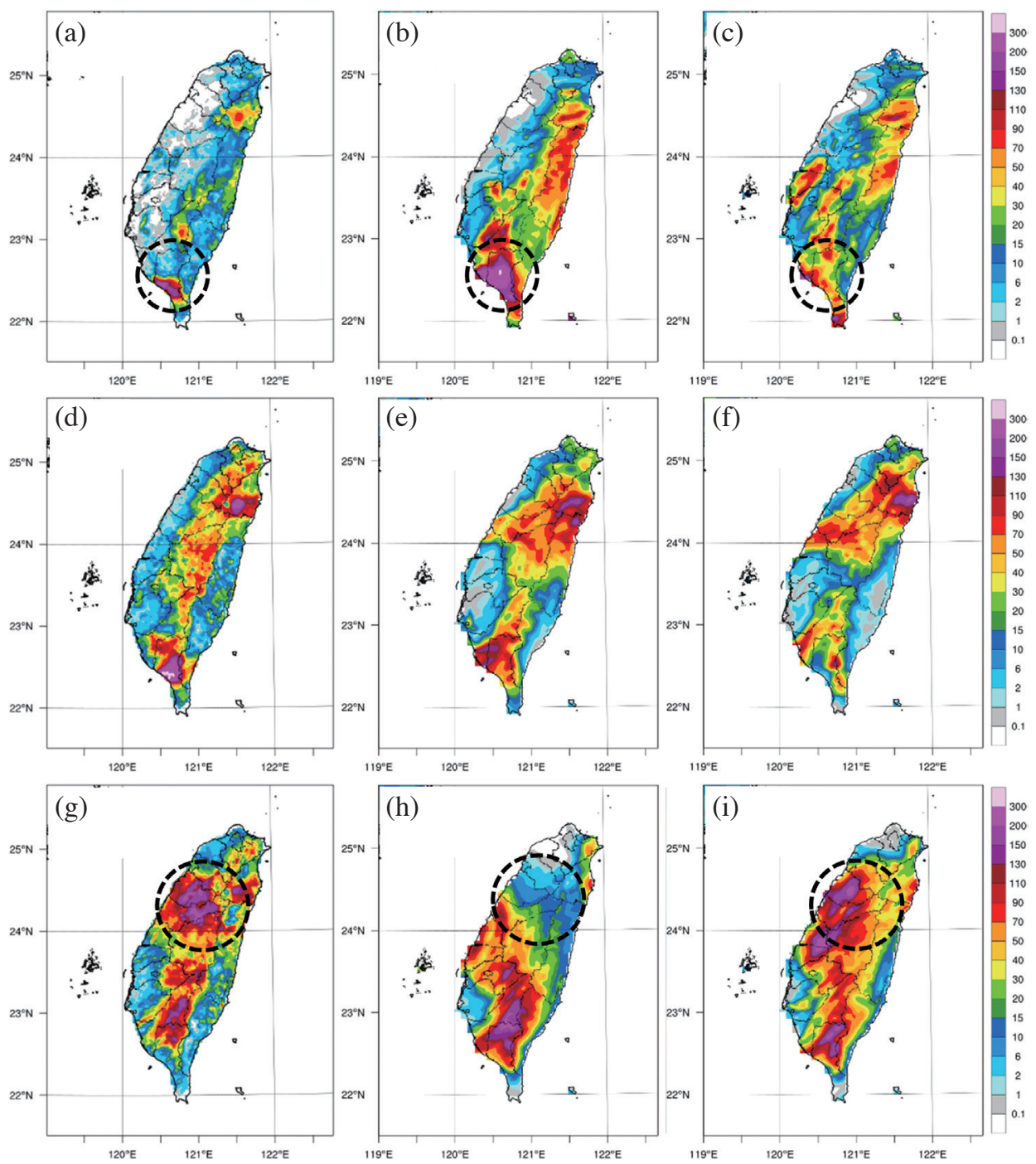

Fig. 13. Six-hour accumulated rainfall (mm; color shading on the right) for 0 - 6 hours in top panels (a) (b) (c) 6 - 12 hours in middle panels (d) (e) (f), and 12 - 18 hours in bottom panels (g) (h) (i), where the left column (a) (d) (g) is the observations as estimated by QPESUM, and the middle (b) (e) (h), and the right (c) (f) (i) columns are for the CTRL00 and the FDDA+4h00 forecast starting on 0000 UTC 29 July. Some key differences in the rainfall are highlighted with dashed circles (see text for discussion).

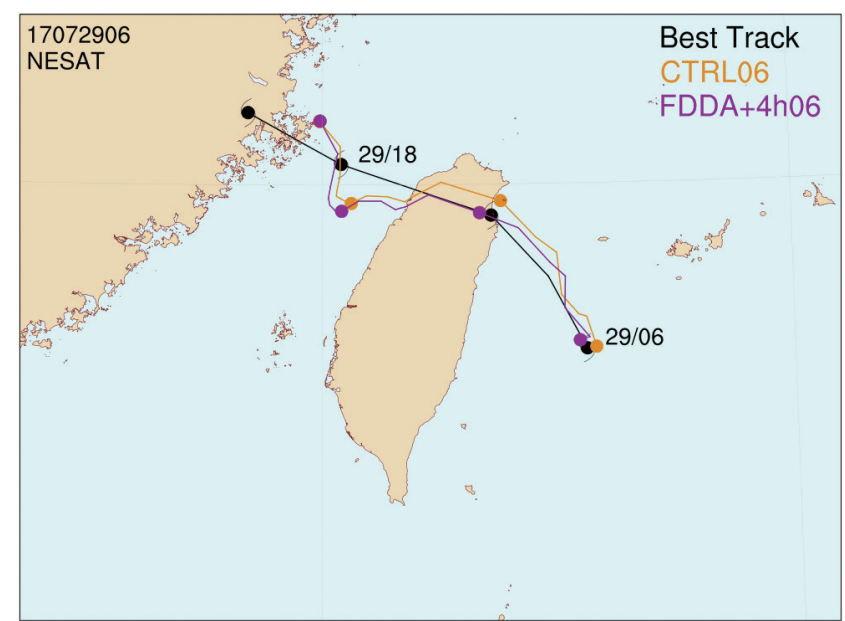

Fig. 14. Best track (black), the CTRL06 (orange), and FDDA+4h06 (purple) forecast tracks for Typhoon Nesat as in Fig. 11 except for the forecasts starting from 0600 UTC 29 July 2017. 
small track errors (Table 2). With the track errors of only about 20 to $80 \mathrm{~km}$ from 6 to $18 \mathrm{~h}$ in the CTRL06, it is expected that the impact of assimilating the radar-wind fields will be less than in the first case. The wind differences between the CTRL06 (top panels) and the FDDA+4h06 forecasts (bottom panels) and the verifications (from the radar data) are shown in Fig. 15. Because the center positions from the two forecasts are very close, the wind difference fields between the forecasts and the verifications have similar patterns. However, the magnitudes of these $3 \mathrm{~km}$ wind differences for the FDDA+4h06 forecast are much reduced relative to the CTRL06 forecast at 1000 UTC and 1200 UTC (Fig. 15b versus Fig. 15e and Fig. 15c versus Fig. 15f, respectively).

The comparisons of the radar reflectivity for this case are shown in Fig. 16 where the observations (top panels) are the continuation of the top panels in Fig. 12, while the forecasts (middle and lower panels) start 6 hours later at 0600 UTC 29 July. At 1200 UTC, which is just 6 hours into the integration in this case, the eye of Nesat has just made landfall on the northeastern Taiwan coast (Fig. 14). The simulated reflectivity pattern defines well the eye in the CTRL06 forecast after just 6 hours, although center position is slightly to the north of the best-track position (Fig. 14). In the FDDA+4h06 forecast, Nesat has already made landfall (Fig. 14), and therefore the simulated radar reflectivity pattern (Fig. 16g) does not reveal the eye at this time. Two hours later at 1400 UTC, both model forecasts have predicted the storm center to be at the northwest coast of Taiwan (Fig. 14). Consequently, the storm circulation is not well organized and the simulated radar reflectivity patterns are disorganized in both the CTRL06 (Fig. 16e) and the FDDA+4h06 (Fig. 16h). By 1600 UTC, Nesat has just left the land and the simulated radar reflectivity patterns from the two forecasts are similar. Overall, the instantaneous rainfall patterns from the CTRL06 and FDDA+4h06 radar reflectivity forecasts are very similar, which might be expected due to their close storm positions while passing over the northern tip of Taiwan.

The 6-hour accumulated rainfall for the $0-6,6-12$, and 12 - 18 hours periods starting from 0600 UTC 29 July are provided in the upper, middle, and bottom panels of Fig. 17, respectively. The observed accumulated rainfall as estimated by QPESUM is provided in the left column and
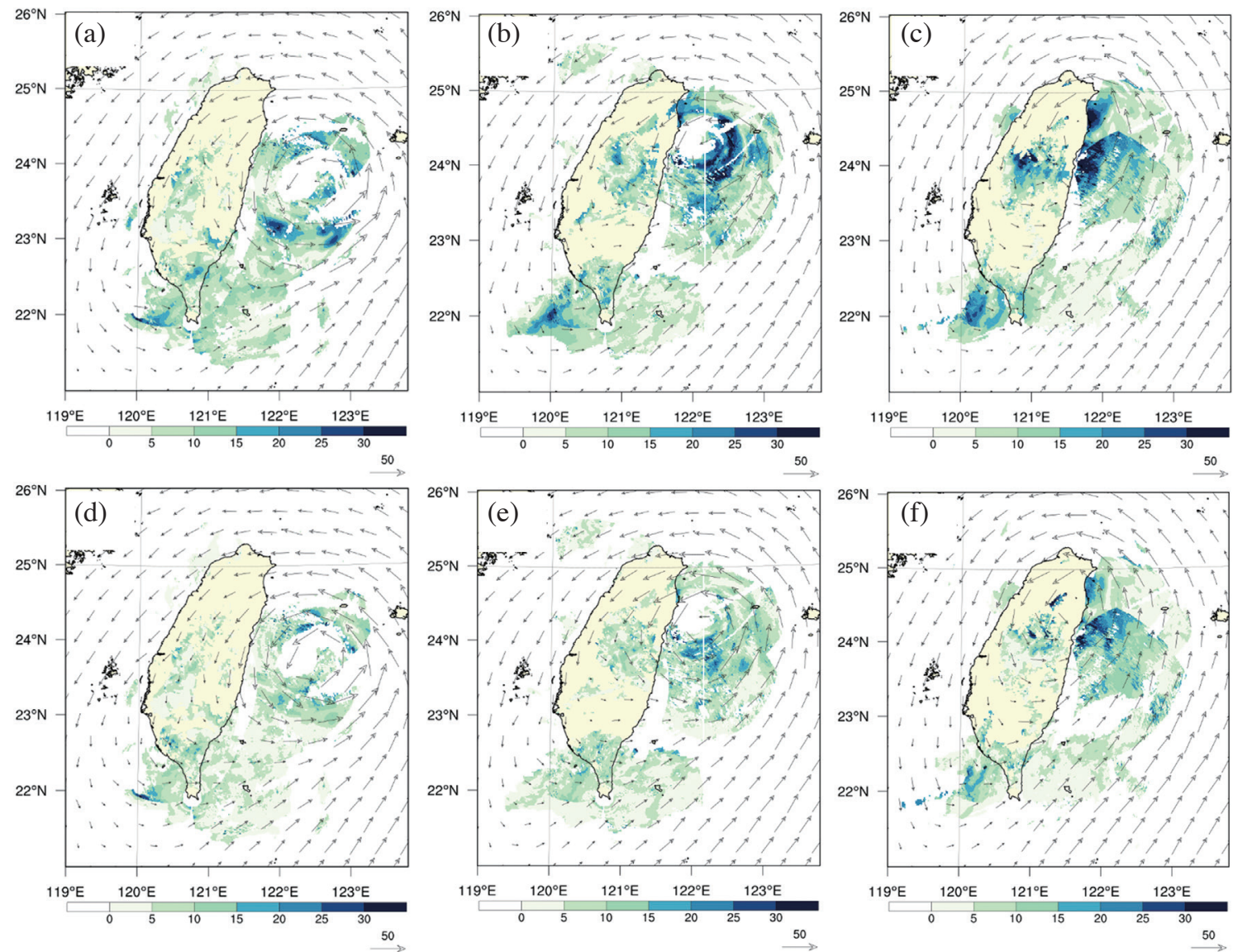

Fig. 15. Forecast $3 \mathrm{~km}$ wind vector fields $\left(\mathrm{m} \mathrm{s}^{-1}\right)$ and differences from the radar-retrieval winds, as in Fig. 10, except for $0800 \mathrm{UTC}$ (a) (d), 1000 UTC (b) (e), and 1200 UTC (c) (f) starting from 0600 UTC 29 July. The upper panels are from the CTRL06 forecasts without FDDA and the lower panels are from FDDA+4h06 forecasts. 

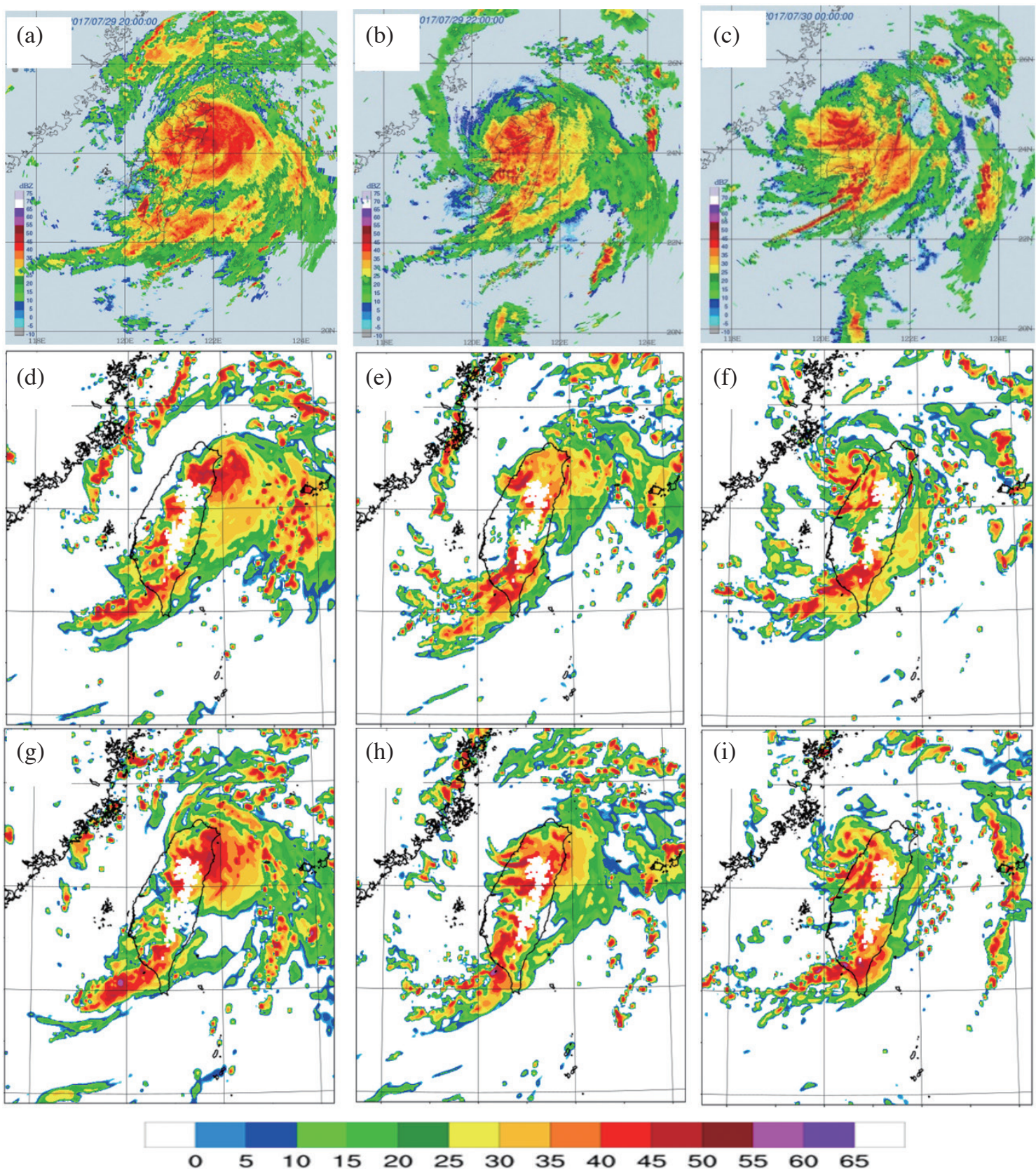

Fig. 16. Simulated radar reflectivity (dBZ) in top panels (a) (b) (c): observations; middle panels (d) (e) (f): CTRL06 forecast; bottom panels (g) (h) (i): forecast of FDDA+4h06 as in Fig. 12, except for 1200 UTC, 1400 UTC, and 1600 UTC, and the forecasts were started from 0600 UTC 29 July. 

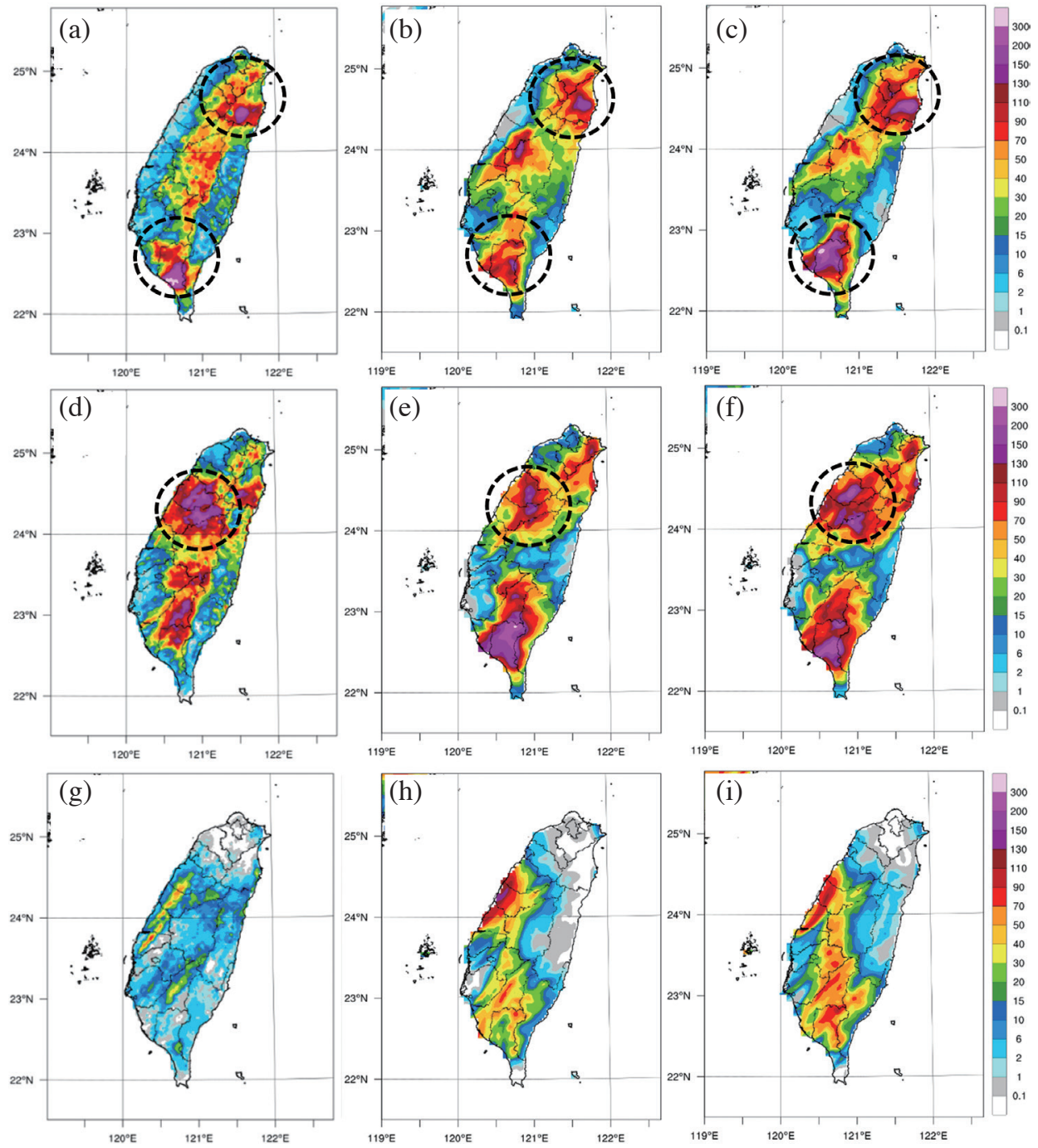

Fig. 17. Six-hour accumulated rainfall for 0 - 6, 6 - 12, and 12 - 18 hours, where the left columns (a) (d) (g) provides the observations, and the middle columns (b) (e) (h) and the right columns (c) (f) (i) are for the CTRL06 and the FDDA+4h06 forecasts, same as in Fig. 13 except for initiated at 0600 UTC 29 July 2017. Some key differences in the rainfall are highlighted with dashed circles (see text for discussion).

has maximum in both the northern and southern regions during the $0-6$ hours period (Fig. 17a), a predominant maximum in the north-central region during the $6-12$ hours period (Fig. 17d), and essentially no Nesat-related rainfall during the 12 - 18 hours period (Fig. 17g). During the 0 6 hours period, the accumulated rainfall maximum forecast from the FDDA+4h06 (Fig. 17c) are better than from the CTRL06 (Fig. 17b) for the Nesat-related northern Taiwan maximum (likely due to the 0 - 4 hours continued assimilation), but has excessive rainfall in the southern Taiwan maximum. During the $6-12$ hours period, the Nesat-related accumulated rainfall maximum in the north-central region is better forecast from the FDDA+4h06 (Fig. 17f) than from the CTRL06 (Fig. 17e). The near-zero accumulated rainfall in the north-central coastal region (Fig. 17g) during the $12-18$ hours period is not predicted well by either the CTRL06 or the FDDA+4h06, as both have excessive rainfall
(Figs. 17h and i), which may be attributed to their southward track deviations at 18 UTC 29 July (Fig. 14).

Overall, the impacts of the FDDA+4h06 forecasts for this second period starting from 0600 UTC 29 July are smaller than in the first period in section 3.1, but this may be attributed to the control TWRF (CTRL06) forecast being so good during this period. There were also smaller terrain-effects on the accumulated precipitation during the second period.

\section{SUMMARY AND CONCLUSION}

The main purpose of this study has been to demonstrate the impact of assimilating radar-retrieved winds using FDDA to improve the precipitation and wind distribution when Typhoon Nesat was near Taiwan. Since TWRF has shown significant improvement of its performance on both 
the track and intensity with high resolutions in the current operational model (Hsiao et al. 2020), further improvements and demonstration of the impacts of assimilating additional data has been a challenge. However, even a small improvement in the track prediction can result in better predictions of the wind and precipitation distributions, which can be very beneficial to the society due to the small size of the island and the unevenly distributed population on the Taiwan island on which $70 \%$ is covered by mountains.

The effect of assimilating the radar-retrieved wind data has been examined for Typhoon Nesat (2017), which crossed Taiwan in July 2017 with ample Doppler radar data collected during the time. After quality control and data thinning, the radar retrieval wind data are assimilated through the efficient FDDA nudging method. The nudging is conducted after the completion of existing hybrid 3DEnVar in TWRF forecast system, for all standard observational data and thus combines the ensemble and variational methods. The key feature here is a new strategy by taking advantage of the 4-h waiting time for the completion of the global model prediction that is required to provide the lateral boundary conditions for TWRF, which allows for the collection of more radar wind observations for inclusion in the TWRF initial conditions. In this new strategy, radar data that have become available within the 4 hours waiting window can continue to be assimilated using the FDDA (FDDA+4h) before launching the forecast at synoptic time plus 4 hours.

Two forecasts starting from 0000 UTC and from 0600 UTC 29 July 2017 are examined when Typhoon Nesat was initially just to the east of Taiwan and then made landfall within $24 \mathrm{~h}$. Due to the proximity of the typhoon to the island, the eight sets of dual-Doppler wind analyses from seven radars were able to provide good data coverage of the storm structure for both initialization and validation. For the 0000 UTC case, the CTRL00 forecast track errors were $86 \mathrm{~km}$ at 12-hour, $105 \mathrm{~km}$ at 18-hour, and $80 \mathrm{~km}$ at 24hour, respectively. By contrast, the FDDA $+4 \mathrm{~h} 00$ forecast had track errors of only $59 \mathrm{~km}$ at 12-hour, $78 \mathrm{~km}$ at 18 hour, and $78 \mathrm{~km}$ at 24-hour, respectively. Comparisons of the $3 \mathrm{~km}$ wind fields in the CTRLO0 and the FDDA+4h00 forecasts indicate that the assimilation of additional radarretrieved winds during the first 4-hour of integration has a lasting effect of improving the track prediction beyond the data assimilation window. Given the small size of the Taiwan island (roughly $200 \mathrm{~km}$ by $400 \mathrm{~km}$ ), and with the population on the island largely concentrated along the west coast, even these small track forecast improvements can have a benefit for disaster preparedness. Similarly, a small shift in where the typhoon winds are impinging on the Central Mountain Range can result in large differences on the precipitation distribution. For the 0000 UTC case, the FDDA+4h00 forecast improved the two 6 hours accumulated rainfall maxima relative to the CTRL00 forecast, which appears to be mainly due to a small improvement of the track. Specifically, the $6 \mathrm{~h}$ accumulated rainfall between 1200 UTC and 1800 UTC is predicted to be in the southeastern Taiwan in the CTRLO0 forecast, while the FDDA +4 h00 forecast has the accumulated precipitation maxima in the central to northwest part of Taiwan where the population is dense.

For the second 0600 UTC case, the improvements in the accumulated precipitation distributions from the FDDA+4h06 forecast over the CTRL06 forecast are smaller than in the first case, which is due mainly to the small differences between the track forecasts of the CTRL06 and the FDDA+4h06. This is because the CTRL06 track forecast is already very close to the observed track, which allows little room for further improvement. However, assimilation of the dual-Doppler wind fields using the FDDA+4h data assimilation system was still able to improve the distribution of the 6-hour Nesat-related accumulated rainfall, although some excessive terrain-related precipitation remained. As this excessive precipitation may be associated with the microphysics scheme that is used in the TWRF forecast model, different model physical packages will be investigated in the future.

The results in this study of the impact of assimilating the dual-Doppler radar-retrieval wind data demonstrate the potential operational application in the future. The focus should be on improving nowcasting and short-term rainfall forecasts, which requires highly accurate specification of the initial conditions (Sun et al. 2014). The advantages of this data assimilation system are that it is computationally efficient and can be applied in highly localized areas depending on the radar data availability. The limitation of this application for typhoon rainfall prediction is the requirement that the storm needs to be close to Taiwan to have sufficient radar coverage. However, it is when the typhoon is close to the island that the heavy precipitation is occurring, so is not a large limitation. Future applications of this technology may include assimilation of radar reflectivity data through hydrometer latent heat nudging (Pan et al. 2015a). Another application of this FDDA+4h system might be prediction of summer afternoon severe rainfalls.

Acknowledgements The authors thank the Central Weather Bureau for providing the computing resources. This study is supported by the Central Weather Bureau, Taiwan, R.O.C. under grant MOTC-CWB-108-M-03 and MOTCCWB-109-M-03.

\section{REFERENCES}

Aksoy, A., S. Lorsolo, T. Vukicevic, K. J. Sellwood, S. D. Aberson, and F. Zhang, 2012: The HWRF Hurricane Ensemble Data Assimilation System (HEDAS) for high-resolution data: The impact of airborne Doppler radar observations in an OSSE. Mon. Weather Rev., 
140, 1843-1862, doi: 10.1175/mwr-d-11-00212.1. [Link]

Anthes, R. A., 1974: Data assimilation and initialization of hurricane prediction models. J. Atmos. Sci., 31, 702719, doi: 10.1175/1520-0469(1974)031<0702:DAAIO $\mathrm{H}>2$.0.CO;2. [Link]

Chang, P.-L., P.-F. Lin, B. J.-D. Jou, and J. Zhang, 2009: An application of reflectivity climatology in constructing radar hybrid scans over complex terrain. J. Atmos. Ocean. Technol., 26, 1315-1327, doi: 10.1175/2009jtecha1162.1. [Link]

Chang, P.-L., W.-T. Fang, P.-F. Lin, and M.-J. Yang, 2019: A vortex-based Doppler velocity dealiasing algorithm for tropical cyclones. J. Atmos. Ocean. Technol., 36, 1521-1545, doi: 10.1175/jtech-d-18-0139.1. [Link]

Chang, P.-L., J. Zhang, Y.-S. Tang, L. Tang, P.-F. Lin, C. Langston, B. Kaney, C.-R. Chen, and K. Howard, 2021: An Operational Multi-Radar Multi-Sensor QPE System in Taiwan. Bull. Amer. Meteorol. Soc., 102, E555-E577, doi: 10.1175/BAMS-D-20-0043.1. [Link]

Dilley, M., R. S. Chen, U. Deichmann, A. L. Lerner-Lam, and M. Arnold, 2005: Natural Disaster Hotspots: A Global Risk Analysis, World Bank, Washington, DC. Available at https://openknowledge.worldbank.org/ handle/10986/7376.

Elsberry, R. L., J. W. Feldmeier, H.-J. Chen, M. Peng, C. S. Velden, and Q. Wang, 2020: Challenges and Opportunities with New Generation Geostationary Meteorological Satellite Datasets for Analyses and Initial Conditions for Forecasting Hurricane Irma (2017) Rapid Intensification Event. Atmosphere, 11, 1200, doi: 10.3390/atmos11111200. [Link]

Feng, J., J. Sun, and Y. Zhang, 2020: A dynamic blending scheme to mitigate large-scale bias in regional models. J. Adv. Model. Earth Syst., 12, e2019MS001754, doi: 10.1029/2019MS001754. [Link]

Gunter, W. S., J. L. Schroeder, and B. D. Hirth, 2015: Validation of Dual-Doppler Wind Profiles with in situ Anemometry. J. Atmos. Ocean. Technol., 32, 943-960, doi: 10.1175/jtech-d-14-00181.1. [Link]

Hendricks, E. A., Y. Jin, J. R. Moskaitis, J. D. Doyle, M. S. Peng, C.-C. Wu, and H.-C. Kuo, 2016: Numerical simulations of Typhoon Morakot (2009) using a multiply nested tropical cyclone prediction model. Weather Forecast., 31, 627-645, doi: 10.1175/waf-d-15-0016.1. [Link]

Hoke, J. E. and R. A. Anthes, 1976: The initialization of numerical models by a dynamic-initialization technique. Mon. Weather Rev., 104, 1551-1556, doi: 10.1175/1520-0493(1976)104<1551:TIONMB>2.0. CO;2. [Link]

Hsiao, L.-F., C.-S. Liou, T.-C. Yeh, Y.-R. Guo, D.-S. Chen, K.-N. Huang, C.-T. Terng, and J.-H. Chen, 2010: A Vortex Relocation Scheme for Tropical Cyclone Ini- tialization in Advanced Research WRF. Mon. Weather Rev., 138, 3298-3315, doi: 10.1175/2010MWR3275.1. [Link]

Hsiao, L.-F., D.-S. Chen, Y.-H. Kuo, Y.-R. Guo, T.-C. Yeh, J.-S. Hong, C.-T. Fong, and C.-S. Lee, 2012: Application of WRF 3DVAR to operational typhoon prediction in Taiwan: Impact of outer loop and partial cycling approaches. Weather Forecast., 27, 1249-1263, doi: 10.1175/WAF-D-11-00131.1. [Link]

Hsiao, L.-F., X.-Y. Huang, Y.-H. Kuo, D.-S. Chen, H. Wang, C.-C. Tsai, T.-C. Yeh, J.-S. Hong, C.-T. Fong, and C.-S. Lee, 2015: Blending of global and regional analyses with a spatial filter: Application to typhoon prediction over the western North Pacific Ocean. Weather Forecast., 30, 754-770, doi: 10.1175/WAFD-14-00047.1. [Link]

Hsiao, L.-F., D.-S. Chen, J.-S. Hong, T.-C. Yeh, and C.-T. Fong, 2020: Improvement of the Numerical Tropical Cyclone Prediction System at the Central Weather Bureau of Taiwan: TWRF (Typhoon WRF). Atmosphere, 11, 657, doi: 10.3390/atmos11060657. [Link]

Huang, Y., Y. Liu, M. Xu, Y. Liu, L. Pan, H. Wang, W. Y. Y. Cheng, Y. Jiang, H. Lan, H. Yang, X. Wei, R. Zong, and C. Cao, 2018: Forecasting severe convective storms with WRF-based RTFDDA radar data assimilation in Guangdong, China. Atmos. Res., 209, 131-143, doi: 10.1016/j.atmosres.2018.03.010. [Link]

Korsholm, U. S., C. Petersen, B. H. Sass, N. W. Nielsen, D. G. Jensen, B. T. Olsen, R. Gill, and H. Vedel, 2015: A new approach for assimilation of $2 \mathrm{D}$ radar precipitation in a high-resolution NWP model. Meteorol. Appl., 22, 48-59, doi: 10.1002/met.1466. [Link]

Li, X., J. Ming, Y. Wang, K. Zhao, and M. Xue, 2013: Assimilation of T-TREC-retrieved wind data with WRF 3DVAR for the short-term forecasting of typhoon Meranti (2010) near landfall. J. Geophys. Res., 118, 10,361-10,375, doi: 10.1002/jgrd.50815. [Link]

Li, Y., X. Wang, and M. Xue, 2012: Assimilation of radar radial velocity data with the WRF hybrid ensemble3DVAR system for the prediction of hurricane Ike (2008). Mon. Weather Rev., 140, 3507-3524, doi: 10.1175/mwr-d-12-00043.1. [Link]

Liu, Y., F. Chen, T. Warner, and J. Basara, 2006: Verification of a mesoscale data-assimilation and forecasting system for the Oklahoma City area during the Joint Urban 2003 Field Project. J. Appl. Meteorol. Climatol., 45, 912-929, doi: 10.1175/jam2383.1. [Link]

Liu, Y., T. T. Warner, J. F. Bowers, L. P. Carson, F. Chen, C. A. Clough, C. A. Davis, C. H. Egeland, S. F. Halvorson, T. W. Huck, L. Lachapelle, R. E. Malone, D. L. Rife, R.-S. Sheu, S. P. Swerdlin, and D. S. Weingarten, 2008a: The operational mesogamma-scale analysis and forecast system of the U.S. Army Test and Evaluation Command. Part I: Overview of the 
modeling system, the forecast products, and how the products are used. J. Appl. Meteorol. Climatol., 47, 1077-1092, doi: 10.1175/2007jamc1653.1. [Link]

Liu, Y., T. T. Warner, E. G. Astling, J. F. Bowers, C. A. Davis, S. F. Halvorson, D. L. Rife, R.-S. Sheu, S. P. Swerdlin, and M. Xu, 2008b: The operational mesogamma-scale analysis and forecast system of the U.S. Army Test and Evaluation Command. Part II: Interrange comparison of the accuracy of model analyses and forecasts. J. Appl. Meteorol. Climatol., 47, 10931104, doi: 10.1175/2007jamc1654.1. [Link]

Pan, L., Y. Liu, Y. Liu, P. Child, and N. Jacobs, 2015a: Development of a CONUS radar data assimilation WRF-RTFDDA system for convection-resolvable analysis and prediction. 16th WRF Annual User's Workshop, NCAR, Boulder, Colo., doi: 10.13140/ RG.2.1.2765.4166. [Link]

Pan, L., Y. Liu, Y. Liu, L. Li, Y. Jiang, W. Cheng, and G. Roux, 2015b: Impact of four-dimensional data assimilation (FDDA) on urban climate analysis. J. Adv. Model. Earth Syst., 7, 1997-2011, doi: 10.1002/2015ms000487. [Link]

Skamarock, W. C., J. B. Klemp, J. Dudhia, D. O. Gill, D. Barker, M. G. Duda, X. Huang, W. Wang, and J. G. Powers, 2008: A description of the Advanced Research WRF version 3. No. NCAR/TN-475+STR, NCAR Technical Note, University Corporation for Atmospheric Research, 113 pp, doi: 10.5065/D68S4MVH. [Link]

Stauffer, D. R. and N. L. Seaman, 1990: Use of four-dimensional data assimilation in a limited-area mesoscale model. Part I: Experiments with synopticscale data. Mon. Weather Rev., 118, 1250-1277, doi: 10.1175/1520-0493(1990)118<1250:UOFDDA >2.0. $\mathrm{CO} ; 2$. [Link]

Stauffer, D. R. and N. L. Seaman, 1994: Multiscale fourdimensional data assimilation. J. Appl. Meteorol. Climatol., 33, 416-434, doi: 10.1175/1520-0450(1994) 033<0416:MFDDA>2.0.CO;2. [Link]

Stephan, K., S. Klink, and C. Schraff, 2008: Assimilation of radar-derived rain rates into the convective-scale model COSMO-DE at DWD. Q. J. R. Meteorol. Soc., 134, 1315-1326, doi: 10.1002/qj.269. [Link]

Sun, J., M. Xue, J. W. Wilson, I. Zawadzki, S. P. Ballard, J. Onvlee-Hooimeyer, P. Joe, D. M. Barker, P.-W. Li, B.
Golding, M. Xu, and J. Pinto, 2014: Use of NWP for Nowcasting Convective Precipitation: Recent Progress and Challenges. Bull. Amer. Meteorol. Soc., 95, 409426, doi: 10.1175/bams-d-11-00263.1. [Link]

Wang, M., M. Xue, and K. Zhao, 2016: The impact of T-TREC-retrieved wind and radial velocity data assimilation using EnKF and effects of assimilation window on the analysis and prediction of Typhoon Jangmi (2008). J. Geophys. Res., 121, 259-277, doi: 10.1002/2015JD024001. [Link]

Weng, Y. and F. Zhang, 2012: Assimilating airborne Doppler radar observations with an ensemble Kalman filter for convection-permitting hurricane initialization and prediction: Katrina (2005). Mon. Weather Rev., 140, 841-859, doi: 10.1175/2011mwr3602.1. [Link]

Wu, C.-C. and Y.-H. Kuo, 1999: Typhoons affecting Taiwan: Current understanding and future challenges. Bull. Amer. Meteorol. Soc., 80, 67-80, doi: 10.1175/1520-0477(1999)080<0067:TATCUA>2.0. CO;2. [Link]

Xiao, Q., Y.-H. Kuo, J. Sun, W.-C. Lee, D. M. Barker, and E. Lim, 2007: An approach of radar reflectivity data assimilation and its assessment with the inland QPF of Typhoon Rusa (2002) at landfall. J. Appl. Meteorol. Climatol., 46, 14-22, doi: 10.1175/jam2439.1. [Link]

Yang, X., 2005: Analysis blending using spatial filter in grid-point model coupling. HIRLAM Newsletter, 48, 49-55.

Zhang, F., Y. Weng, J. A. Sippel, Z. Meng, and C. H. Bishop, 2009: Cloud-resolving hurricane initialization and prediction through assimilation of Doppler radar observations with an ensemble Kalman filter. Mon. Weather Rev., 137, 2105-2125, doi: 10.1175/2009mwr2645.1. [Link]

Zhao, K., X. Li, M. Xue, B. J.-D. Jou, and W.-C. Lee, 2012a: Short-term forecasting through intermittent assimilation of data from Taiwan and mainland China coastal radars for Typhoon Meranti (2010) at landfall. J. Geophys. Res., 117, D06108, doi: 10.1029/2011JD017109. [Link]

Zhao, K., M. Xue, and W.-C. Lee, 2012b: Assimilation of GBVTD-retrieved winds from single-Doppler radar for short-term forecasting of super typhoon Saomai (0608) at landfall. Q. J. R. Meteorol. Soc., 138, 10551071, doi: 10.1002/qj.975. [Link] 